\title{
COORDINACIÓN Y CONTROVERSIA ENTRE ÓRGANOS ENCARGADOS DE RESOLVER SOBRE DISPUTAS TRIBUTARIAS EN MATERIA DE PATENTES MUNICIPALES: CONTRALORÍA GENERAL DE la RePÚblicA, CORTES DE APElaCiONES, CORTE SUPREMA Y TRIBUNAL CONSTITUCIONAL ${ }^{*}$
}

\section{Patricio Masbernat Muñoz**}

RESUMEN: El presente trabajo expone y analiza las diferentes perspectivas jurídicas de las decisiones de la jurisdicción ordinaria (Cortes de Apelaciones y Suprema), de las decisiones de la administración estatal correspondiente (Contraloría General de la República) y de la jurisdicción constitucional relativa a la aplicación de la tributación local (patentes municipales) a las sociedades de inversión pasiva, destacando los elementos de desacuerdo entre los diferentes órganos administrativos y judiciales competentes para su solución, como el resultado que se cristaliza en el actual estado de la cuestión. El autor destaca cómo se han ido uniformando las decisiones de los órganos públicos involucrados, no obstante que la ley parece dar lugar a diferentes soluciones posibles frente al mismo tipo de casos.

PALABRAS CLAVE: Tributación local, patentes municipales, decisión judicial, decisión administrativa.

\section{COORDINATION AND CONTROVERSY BETWEEN PUBLIC BODIES RESPONSIBLE FOR RESOLVING TAX DISPUTES IN MATTERS OF LOCAL TAXATION: COMPTROLLER GENERAL OF THE REPUblic, COURTS OF APPEALS, Supreme CoURT, AND CONSTITUTIONAL COURT}

ABSTRACT: This paper exposes and analyses the different legal perspectives of the decisions of the ordinary jurisdiction (Courts of Appeals and Supreme Court of Justice), the decisions of the

\footnotetext{
* Fecha de recepción: 11 de mayo de 2017.

Fecha de aceptación: 13 de marzo de 2018.

** Doctor en Derecho por la Universidad Complutense de Madrid. Profesor de Derecho Universidad Autónoma de Chile (Chile).Correo electrónico: patricio.masbernat@uautonoma.cl
} 
public administration (Comptroller General of the Republic) and the constitutional jurisdiction (Constitutional Court and Supreme Court) regarding the application of the (Municipal patents) to passive investment companies, highlighting the elements of disagreement between the different administrative and judicial bodies competent for their solution, as the result that is crystallized in the current state of the matter. The author emphasizes how the decisions of the public bodies involved have become uniform, notwithstanding that the law seems to allow different possible solutions to the same type of cases.

KEY WORDS: Local taxation, municipal taxes, judicial decision, administrative decision.

Sumario: Introducción. (1.) La postura de la Contraloría General de la República. (2.) La postura de las Cortes a través de las sentencias en recurso de protección. (3.) La postura expresada en las sentencias del Tribunal Constitucional. (4.) Sentencias recientes de la Corte Suprema en recurso de casación. Conclusiones.

\section{INTRODUCCIÓN ${ }^{1}$}

Desde hace varios años ha existido una disputa interpretativa relativa a si las "sociedades de inversión pasiva" constituyen o no sujetos pasivos de los impuestos locales, i.e., aquella clase de tributos locales denominados en nuestro medio "patentes municipales", establecidos en el Decreto Ley $\mathrm{N}^{\circ} 3.063$, de $1979^{2}$ sobre Rentas Municipales, y sus modificaciones (Ley de Rentas Municipales o LRM, en lo sucesivo) ${ }^{3}$.

La inversión pasiva constituye una categoría que ha sido definida por la Administración, para efectos de determinar sus efectos fiscales, en los siguientes términos: es "la que, en general, consiste en la adquisición de toda clase de bienes con fines rentísticos, sea cual fuere la forma jurídica que adquiera el inversionista, por no involucrar la producción de bienes,

1 Abreviaturas: C: Considerando o Fundamento Jurídico; CGR: Contraloría General de la República; D.L.: Decreto Ley; D.S.: Decreto Supremo; LRM: Ley de Rentas Municipales; RP: Recurso de Protección (tipo de acción de amparo de derechos fundamentales sustanciado ante Cortes de Apelaciones y Corte Suprema); TC: Tribunal Constitucional; STC: Sentencia del TC.

2 Decreto Ley No 3.063, de 1979, Sobre Rentas Municipales (Publicado en el D.O. de 20 de noviembre de 1996 actualizado al 26 de noviembre de 1999). Se debe considerar también el DL No 527, Reglamento para la aplicación de los artículos $23^{\circ}$ y siguientes del Título IV del D.L. No 3.063, de 1 de agosto de 1980.

3 Hay que destacar que se ha tratado de cobrar patentes municipales también a los individuos que administran sus propias inversiones (ver Dictamen No 43843 de Contraloría General de la República, de 3 de agosto de 2010). 
ni la prestación de servicios, no constituye una actividad que configure el hecho gravado contemplado en el artículo 23 del mencionado decreto ley $N^{\circ} 3.063$, de 1979" (Contraloría General de la República, Dictamen 27.677, de 25 de mayo de 2010). La sociedad de inversión pasiva ha descrita por los Tribunales como la "sociedad cuyo objeto social y giro es la inversión de todo tipo de bienes y que realiza solamente inversiones pasivas percibiendo ingresos por rentabilidad de inversiones no teniendo ingresos por actividades comerciales; sociedad que realiza inversiones pasivas es decir, sin proyección al público o prestando servicios de inversión por los que cobre una determinada comisión (sentencia de Corte de Apelaciones de Santiago de 30 agosto de 2011, "Inversiones El Paso Limitada con Municipalidad de Providencia") ${ }^{4}$.

El debate judicial acerca de estos efectos fiscales de las sociedades pasivas tiene expresiones recientes en diversas sentencias de la Corte Suprema: "I. Municipalidad de Macul con Sociedad Inversiones AF Limitada" (2014) $)^{5}$ "I. Municipalidad de Las Condes con Ximena Merino Blanco I" (2015) ${ }^{6}$; "I. Municipalidad de Las Condes con Ximena Merino Blanco II" (2015)7; "I. Municipalidad de Cerrillos con Renta e Inversiones ARBA" $(2016)^{8}$; "Christian Guillermo Farr Gaete con I. Municipalidad de La Serena" (2017) .

Durante la primera década del presente siglo, los tribunales consideraron que las sociedades de inversión pasiva no se sujetaban a este impuesto, por no transar con terceros ni funcionar en locales o establecimientos, y derivar sus ganancias únicamente de rentas de sus inversiones.

4 Corte de Apelaciones de Santiago, 30 agosto de 2011, Rol No 1092-11, "Inversiones El Paso Limitada con Municipalidad de Providencia”. Disponible en Base de Datos MicroJuris, Cita: MJCH_MJJ29206|ROL:1092-11, MJJ29206 [Fecha de visita: 24 de abril de 2017].

5 Corte Suprema, 9 de abril de 2015, Rol No 24214-2014, "I. Municipalidad de Macul con Sociedad Inversiones AF Limitada”, Recurso de Casación en el Fondo. Disponible en Base de Datos LegalPublishing, Cita Online: CL/JUR/2000/2015. [Fecha de visita: 24 de abril de 2017].

6 Corte Suprema, 29 de diciembre de 2015, Rol No 5765-2015, "I. Municipalidad de Las Condes con Ximena Merino Blanco I", recurso de Casación en el Fondo. Disponible en Base de Datos LegalPublishing, Cita Online: CL/JUR/8114/2015 [Fecha de visita: 24 de abril de 2017].

7 Corte Suprema, 29 de diciembre de 2015, Rol No 5602-2015, "I. Municipalidad de Las Condes con Ximena Merino Blanco II", recurso de casación en el fondo. Disponible en Base de Datos LegalPublishing, Cita Online: CL/JUR/8115/2015 [Fecha de visita: 24 de abril de 2017].

8 Corte Suprema, 5 de diciembre de 2016, Rol No 47588-2016I, "Municipalidad de Cerrillos con Renta e Inversiones ARBA”, recurso de casación en el fondo. Disponible en Base de Datos MicroJuris, Cita Online: MJCH_MJJ47340|ROL: 47588-16, MJJ47340 [Fecha de visita: 24 de abril de 2017].

9 Corte Suprema, 30 de marzo de 2017, Rol No 58992-2016, "Christian Guillermo Farr Gaete con I. Municipalidad de La Serena”, recurso de casación (Reclamo de Ilegalidad). Disponible en Base de Datos LegalPublishing, Cita Online: CL/JUR/1337/2017 [Fecha de visita: 24 de abril de 2017]. 
En el año 2005 se dictó la Ley No $20.033^{10}$, que precisó el domicilio de las sociedades de inversión para los fines del pago de las patentes municipales $^{11}$. Desde dicho evento, progresivamente se comenzó a entender por parte de las Cortes de Apelaciones y la Corte Suprema que las sociedades de inversión con fines de lucro se consideraban empresas de servicios sujetas al impuesto local ${ }^{12}$.

La ley No 20.033, de 1 de julio de 2005, incorpora la mención expresa de las sociedades de inversión como contribuyentes ${ }^{13}$.

10 Ley No 20.033 (1 de julio de 2005), Modifica la Ley No 17.235, Sobre Impuesto Territorial; Decreto Ley No 3.063, sobre Rentas Municipales; la Ley No 18.695, Orgánica Constitucional de Municipalidades, y faculta a las Municipalidades para otorgar condonaciones que indica.

11 La reforma incorpora al final del inciso $1^{\circ}$ del artículo 24, las siguientes oraciones finales: "Tratándose de sociedades de inversiones o sociedades de profesionales, cuando estas no registren domicilio comercial, la patente se deberá pagar en la comuna correspondiente al domicilio registrado por el contribuyente ante el Servicio de Impuestos Internos. Para estos efectos, dicho Servicio aportará esta información a las municipalidades, por medios electrónicos, durante el mes de junio de cada año."

12 Un caso típico que puede mencionarse, es "Inversiones Extranjeras Cementos Bio-Bío con Municipalidad de Providencia I y II”. El contribuyente reclama la ilegalidad del acto administrativo que establece el cobro del impuesto, luego apela al fallo desestimatorio, y luego recurre de casación en contra del segundo. En lo esencial, la Corte de Apelaciones y la Corte Suprema consideran que el objeto social concreto de una sociedad de inversiones es lo suficientemente amplio como para considerarse incluidas las actividades terciarias lucrativas gravables, con independencia de que optara o no llevarlas a cabo, y de no llevarla a cabo ello no era oponible al Municipio; aunque efectivamente en alguna oportunidad prestó servicios a terceros (sus socios); y efectivamente efectuaba actividades lucrativas ya que era un contribuyente de impuesto a la renta de primera categoría y obtenía ganancias, y desarrollaba actos de comercio en su carácter de sociedad anónima. Procedía el cobro del impuesto local aunque no efectuara actividades terciarias gravadas, no contara con personal, no prestara servicios a terceros, no emitiera facturas, no contara con establecimiento o local.

13 Historia de la Ley. Primer Informe de la Comisión de Gobierno Interior, Regionalización, Planificación y Desarrollo Social, Recaido en el Proyecto de Ley que Modifica la Ley $N^{\circ}$ 17.235, Sobre Impuesto Territorial; El Decreto Ley $N^{\circ} 3.063$, Sobre Rentas Municipales; La Ley $N^{\circ}$ 18.695, Orgánica Constitucional de Municipalidades, y Faculta a las Municipalidades para Otorgar las Condonaciones que Indica. Boletín No 2892-06-1. Cámara de Diputados. Fecha 7 de abril, 2003. Cuenta en Sesión 20, Legislatura 349 (páginas 59 y 60 de la Historia de la Ley):

“a) Esta letra, que incorpora dos oraciones finales al inciso primero (que señala que la patente grava la actividad que se ejerce por un mismo contribuyente en su local, oficina o establecimiento), en el sentido de precisar que tratándose de las sociedades de inversiones o de profesionales que no registren domicilio comercial la patente se pagará en la comuna registrada por el contribuyente ante el SII, el que aportará esta información a los municipios en la forma que se señala, fue aprobada por idéntico quórum.

Al margen de precisar que la disposición en comento se limita a perfeccionar el sistema de cobranza de la patente, sin constituir un nuevo impuesto, el representante del Ejecutivo expresó que hoy dia existen aproximadamente 150 mil sociedades de inversiones y de profesionales, gran parte de las cuales no tiene domicilio comercial, lo que dificulta o hace imposible el cobro en cuestión. Dada la considerable evasión tributaria en la materia, por este concepto se espera recaudar unos $\$ 4.500$ millones."

Ref.,: www.bcn.cl/obtienearchivo?id=recursoslegales/10221.3/3873/1/HL20033.pdf (6 abril 2017, Fecha de visita). 
A continuación trazaremos el recorrido de las decisiones judiciales que marcaron el debate, con la participación de la Contraloría General de la República, y del Tribunal Constitucional.

\section{1) La postura de la Contraloría General de la República}

A la Contraloría General de la República (CGR, en adelante) le ha correspondido un importante papel en esta controversia. A dicho organismo, en virtud de su Ley Orgánica Constitucional (LOC), le cabe la función de fiscalizar la actividad de los Municipios. Diversos dictámenes de este organismo ( $\mathrm{N}^{\circ} 12.607$ y $\mathrm{N}^{\circ}$ 54.106, de 2006; $\mathrm{N}^{\circ} 60.459$ de 2008; $\mathrm{N}^{\circ} 37.529$ y $\mathrm{N}^{\circ} 37.957$, de 2009) entendieron que las acciones desarrolladas por sociedades de inversión constituían una actividad lucrativa terciaria, afecta, por tanto, a la contribución de patente municipal.

Este criterio fue modificado por la CGR, mediante Dictamen $\mathrm{N}^{\circ}$ 27.677/2010. En dicho pronunciamiento, el órgano fiscalizador sostuvo que la inversión pasiva, sea cual fuere la forma jurídica que adquiera el inversionista, no constituía una actividad que configurara el hecho gravado contemplado en el artículo 23 de la LRM, por no involucrar la producción de bienes ni la prestación de servicios, razón por la cual no correspondía aplicarle tributo municipal. En resguardo de la seguridad jurídica y estabilidad de las relaciones jurídicas, a juicio de la CGR, ese dictamen solo tenía efectos para el futuro, por lo que no afectaba las situaciones acaecidas durante la vigencia de la doctrina que sustituía (tenía esos efectos en el tiempo, conforme a dictámenes $\mathrm{N}^{\circ} 65.125 / 2009, \mathrm{~N}^{\circ}$ 4.168/2008, N 50.185/2007, N54.892/2005).

A partir de dicho instante, se produjo una permanente disputa entre los criterios de la CGR y la Corte Suprema, zanjada caso a caso por esta última a favor de las Municipalidades mediante recursos de protección en resguardo del derecho de propiedad sobre los impuestos recaudados por ellas.

En medio de este escenario, algunos contribuyentes acudieron al Tribunal Constitucional (TC en adelante) a objeto de, en el marco de casos semejantes, hacer respetar su perspectiva de los principios constitucionales tributarios y, a través de dicha vía, sus derechos constitucionales (básicamente, los de propiedad e igualdad).

Esto abrió paso a otras estrategias por las cuales algunos alcaldes optaron, y que mencionaremos a continuación.

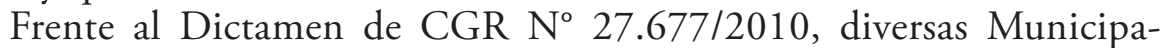
lidades presentaron una solicitud de reconsideración del mismo, lo que fue contestado con la emisión del Dictamen No 6512 de 1 de febrero de 2012, a través del cual la CGR mantuvo el criterio. 
En contra de este nuevo dictamen algunos municipios recurrieron de protección (nótese la estrategia para renovar el plazo para interponer el RP), a raíz de lo cual la Corte de Apelaciones de Santiago (en junio de 2012) y la Corte Suprema (en noviembre de 2012) dictaron las sentencias que son objeto del presente comentario. A través de ellas, las Cortes chilenas intentaron cerrar definitivamente la disputa. La CGR ha tomado nota inmediata del intenso contenido de dichos fallos, reconsiderando una serie de dictámenes en orden a alinearlos a las directrices de la Corte Suprema (Dictamen 71.250 de 16 de noviembre de 2012).

Debe ponerse de relieve que hay un asunto de carácter financiero muy grande en medio de estas disputas interpretativas, pues las Municipalidades recolectan cerca de $\mathrm{MM} \$ 30.000$ anuales por impuestos locales a sociedades de inversión pasivas (cerca de MMU\$S50). Dadas estas altas sumas, algunos parlamentarios (de la Cámara de Diputados) han calificado como "extremadamente preocupante" el criterio sustentado por la CGR.

Es necesario hacer ver que el énfasis del discurso institucional de los órganos públicos involucradas en estos debates se ha referido a la protección de la caja municipal, y en ningún sitio ellos han mencionado -al menos en toda la documentación revisada- los derechos fundamentales del contribuyente ni en general ni en específico (sin embargo, este tema ha sido tratado como una cuestión de derechos fundamentales, de las municipalidades).

En agosto de 2012, luego de la sentencia estimativa de la Corte de Apelaciones de Santiago mencionada, un grupo de diputados presentaron un proyecto de ley interpretativa de la LRM relativa a la expresión "actividad lucrativa terciaria" contenida en su artículo 23, precisando que las sociedades de inversión deben entenderse comprendidas en ella y se encuentran, por tanto, gravadas con impuestos locales (Boletín $\mathrm{N}^{\circ} 8482$ 06, Cámara de Diputados, Legislatura 360, Sesión No 65, 2 de agosto de 2012 $)^{14}$. Los parlamentarios que presentaron esta iniciativa, justifican el Proyecto de Ley en que no obstante la precisión de la jurisprudencia judicial, los municipios han demandado la necesidad de contar con una absoluta certeza y claridad respecto de la materia, evitando que, en lo sucesivo, interpretaciones jurisprudenciales o administrativas puedan afectar la recaudación de estos recursos. Asimismo, los congresistas hacen constar que esta iniciativa legislativa no significa, en caso alguno, reconocer omi-

14 Boletín N 8482-06, Cámara de Diputados, Legislatura 360, Sesión No 65, 2 de agosto de 2012. "PROYECTO DE LEY. Artículo único. Declárese interpretando el artículo 23 del D.L. 3.063 de 1979 que se entiende por actividad lucrativa terciaria toda aquella que produzca utilidad o ganancia y no sea considerada como primaria ni secundaria; lo que incluye, entre otras, las sociedades de inversión y las sociedades de profesionales, cualquiera sea su naturaleza, denominación y la actividad del contribuyente respectivo, encontrándose, por tanto, gravadas con las patentes a que hace referencia dicha disposición.” 
sión ni falta de certeza en los textos vigentes, sino responde al interés de zanjar de un modo indubitado el asunto.

A partir de dichas circunstancias, la CGR ha aplicado inalterablemente la doctrina establecida dictamen de CGR $\mathrm{N}^{\circ} 27.677$, como es posible observar en los casos mencionados en los dictámenes No 63071/2013, No 63073/2013, No 31819/2014, etc.

\section{2) LA POSTURA de las CORTES a traVÉs de SENTENCIAS EN RECURSO DE PROTECCIÓN (LEADING CASES)}

\section{(2.1.) SENTENCIA “CONTRALORÍA GENERAL CON MUNICIPALIDADES de Vitacura, Providencla, Macul y LA GRANJa I” (2012), CoRTE DE APELACIONES DE SANTIAGO ${ }^{15}$}

\section{(2.1.1) Hechos de la causa}

En primera instancia, la Municipalidad de Santiago (luego se hacen parte en el proceso, las Municipalidades de Providencia, Macul, La Granja y la Asociación de Municipalidades) plantea en su recurso de protección (RP, en lo sucesivo) que a la CGR le estaba prohibido pronunciarse sobre asuntos objeto de litigio entre privados y Municipios ante los Tribunales Ordinarios de Justicia, de acuerdo al artículo 6 de la Ley No 10.336 de Organización y Atribuciones de la CGR, y agrega que otro obstáculo procesal es que existen requerimientos de inaplicabilidad pendientes ante el Tribunal Constitucional sobre la materia. Luego de esgrimir el supuesto atentado al derecho de propiedad, el recurso añade que bajo el criterio de la CGR la Municipalidad recurrente debería restituir todas las sumas percibidas desde 1 de julio de 2010, hasta el primer semestre de 2012, que ascienden a un total de $\$ 20.534 .109 .171$ (US\$ 43.596.835, considerando las pagadas y morosas).

Señala que, en los dictámenes impugnados, la CGR crea el concepto de inversión pasiva aplicable a la sociedad de inversión, vulnerando por vía interpretativa una norma legal expresa, textualmente asevera que "carece de facultades para interpretar normas de carácter tributario, como son las que establecen las patentes municipales y menos crear legislación mediante su interpretación”.

La recurrente agrega que con la modificación del artículo 24 de la LRM, incorporada por la ley $\mathrm{N}^{\circ} 20.033$ (que precisó la forma de determi-

15 Corte de Apelaciones de Santiago, 26 de junio de 2012, Rol No 5.776-2012, "Contraloría General con Municipalidades de Vitacura, Providencia, Macul y La Granja I”, recurso de protección. Disponible en: http://corte.poderjudicial.cl/SITCORTEPORWEB/ [Fecha de visita: 24 de abril de 2017] 
nar el domicilio de las sociedades de inversión o de profesionales), se corroboró el hecho de que las sociedades de inversión se encontraban sujetas al gravamen. Asimismo, el TC, en sentencia Rol No 1.454-2009 de 20 de julio de 2010, en requerimiento de Inaplicabilidad por Inconstitucionalidad de los artículo 23 y 24 de la LRM, resolvió que la interpretación de las expresiones actividad lucrativa, secundaria, terciaria y actividades primarias o extractivas, incluidas en el artículo 23, como causantes del pago de patente municipal, no quedan comprendidas en el ámbito de atribuciones de la CGR, siendo competencia de los jueces de fondo, esto es, de los Tribunales Ordinarios de Justicia.

En el libelo de presentación del recurso de protección, se solicita que se dejen sin efecto los dictámenes No 6.512/2012, y No 27.677/2010, y que se ordene a la CGR que se abstenga de conocer en lo sucesivo de solicitudes del tenor de las descritas por constituir materias litigiosas o de naturaleza litigiosa que son de competencia de los Tribunales Superiores de Justicia (frente a lo que interpretamos que el recurrente solicita que se dicte una sentencia de efecto universal).

La CGR responde con diversos argumentos: alega la extemporaneidad del recurso; que el asunto es ajeno a la naturaleza del RP por cuanto si ella ha efectuado una errónea interpretación de ley la vía constitucional empleada no es la vía idónea para dirimir la controversia; la falta de legitimación activa de la recurrente; que la recurrente se encuentra sujeta a la fiscalización de la CGR y que por ello debe someterse a las normas y jurisprudencia administrativa emanada de ella; que a través de esta vía la recurrente no puede pretender sustraerse del cumplimiento de lo resuelto por el órgano contralor; que no se configura acción u omisión ilegal o arbitraria con los Dictámenes impugnados; que este asunto carece de naturaleza litigiosa en los términos del artículo $6^{\circ}$ de la Ley $\mathrm{N}^{\circ}$ 10.336, pues no se trata de asuntos particulares sometidos a consideración de la CGR y que, además, sean conocidos por los tribunales. Añade la recurrida que el hecho que el cobro de la patente por las municipalidades haya sido controvertido por vía judicial por distintos contribuyentes no implica la aplicación automática de dicho precepto, en atención al principio del efecto relativo de las sentencias, pues si esas causas se resuelven de forma diferente a la jurisprudencia administrativa impugnada, esta última se mantiene vigente para aquellos que no han sido parte del respectivo procedimiento judicial.

Para la CGR, lo que el artículo 23 de la LRM grava no es toda actividad lucrativa sino los actos o acciones concretos y determinados que, cuando son efectivamente realizados, quedan comprendidos dentro de los hechos gravados descritos en la norma, i.e., la mera obtención de ganancia no transforma a quien la obtiene en sujeto obligado al pago del impuesto. La patente municipal es un tributo y por tanto se encuentra sujeto al principio de legalidad tributaria, por lo que los órganos de la 
Administración no pueden imponer su pago sino solo cuando se producen los elementos de la obligación tributaria expresamente previstos por el legislador: hecho gravado; sujeto obligado; procedimiento para la determinación de la base imponible; la tasa; exenciones; infracciones.

Añade que la modificación de la Ley 20.033 al artículo 24 de la LRM no hizo extensivo el pago de patente municipal a las sociedades de inversión, sino que tuvo por objeto perfeccionar una norma de competencia en el sistema de cobranza, indicando el lugar en donde se debe pagar la patente en caso que efectivamente deba ser pagada.

Para la CGR, la inversión pasiva consiste generalmente en la adquisición de bienes con fines rentísticos, que no involucren la producción de bienes ni la prestación de servicios, no es una actividad que configura el hecho gravado del artículo 23 de la LRM y los dictámenes contra los cuales se recurre "no han manifestado que las sociedades de inversión se encuentren liberadas per se del pago de patente municipal, como lo entiende el recurrente, ya que este último precepto no grava a determinadas formas de organización societaria o empresarial". Por lo tanto, si un contribuyente adopta tal forma societaria, sociedad de inversión, y se advierte que realiza una actividad gravada con patente municipal, estará obligado a su pago.

Tampoco existiría vulneración del derecho de propiedad, al exigirse la devolución de sumas percibidas por las Municipalidades, pues solo han ingresado al patrimonio de ellas las sumas de dinero que satisfacen las condiciones dispuestas por la ley para su legítima percepción. Además, de acuerdo al principio de legalidad de los actos de la Administración (artículos 6 y 7 constitucionales), las municipalidades solo podrán cobrar aquellos tributos cuando se configure el hecho gravado que genera la respectiva obligación de pago.

Respecto del D.S. No 484 de 1980, del Ministerio del Interior, la CGR señala que el Dictamen impugnado "solo expuso el sentido que debe darse al artículo $2^{\circ}$, letra c), del Decreto, indicando que la definición de actividad terciaria contenida en dicho precepto, comprende únicamente el comercio y distribución de bienes y la prestación de servicios de todo tipo". Tampoco la CGR se ha arrogado atribuciones del TC, ya que no ha efectuado una declaración de inconstitucionalidad.

La CGR sostiene que con la emisión del Dictamen No 5.512/2012, no ha excedido su competencia, pues las sociedades que realizan actividades de inversión no siempre están gravadas con patente municipal ya que se gravan a los actos o acciones concretas y determinadas que, efectivamente realizadas, queden comprendidas en los hechos gravados que describe el artículo 23 de la LRM y su Reglamento. La actividad comercial siempre se encuentra gravada con patente municipal y la intermediación financiera es siempre un acto de comercio, por lo que está gravada. Toda actividad lucrativa está sujeta a patente municipal, sea el contribuyente civil o comercial. A través de la 
modificación introducida por Ley No 20.033 al artículo 24 LRM, ha quedado claro que ello no significa que se ha hecho extensivo el pago de patente a las sociedades de inversión ya que se trata de una disposición que perfeccionó una norma de competencia del sistema de cobranza.

El dictamen impugnado tampoco es vinculante para los municipios ni para los Tribunales de Justicia, dado que los dictámenes solo son obligatorios para el caso particular planteado, no pudiendo dársele esta aplicación general, lo que se sustenta en el artículo 9 de la Ley Orgánica Constitucional (LOC) de la CGR (siendo la única excepción a esta regla el artículo 19 de la misma ley).

\section{(2.1.2) Decisión sobre el caso}

Frente a los argumentos de las partes, la Corte plantea lo que se detalla en los siguientes párrafos.

En primer término, desestima el alegato de extemporaneidad en la interposición del RP, afirmando que el plazo se renovó con el pronunciamiento de la CGR sobre el recurso de reconsideración administrativa, conforme a lo dispuesto en la Ley No 19.880/2003, contándose el plazo desde la notificación del Dictamen No 6.512, de 1 febrero 2012, por el cual se confirmó el Dictamen No 27.677, de 25 de mayo de 2010.

A continuación, sostiene que la normativa sobre Rentas Municipales (D.L. No 3.063; D.S. No 484/1980, del Ministerio del Interior; Ley No 20.033) establece que "el ejercicio de toda profesión, oficio, industria, comercio, arte o cualquiera otra actividad lucrativa secundaria o terciaria sea sujeta a una contribución municipal", y que "en caso de las sociedades de inversión o sociedades de profesionales, cuando estas no registren domicilio comercial, la patente se pagará en el domicilio registrado por el contribuyente ante el Servicio de Impuestos Internos", aduciendo que sobre este punto "existe jurisprudencia asentada de la Excma. Corte Suprema de Justicia".

Luego, la Corte abunda en referencias históricas y teóricas al fundamento del principio de reserva legal y del principio de legalidad.

También se refiere a la facultad para interpretar administrativamente la ley en el ámbito tributario, sustentando que está entregada exclusivamente al Director del Servicio de Impuestos Internos (SII, en adelante), conforme lo disponen el artículo $6^{\circ}$, letra A, No $1^{\circ}$, del Código Tributario y la Ley Orgánica de dicho Servicio. Agrega que dicha interpretación administrativa de la ley tributaria solo obliga a los funcionarios de dicho servicio y a otras autoridades, no siendo obligatoria para los contribuyentes ni para los Tribunales Ordinarios de Justicia. Por tanto, no existe facultad alguna de la CGR para realizar interpretaciones sobre materias tributarias, como es la LRM, y menos aún para declarar que determinadas actividades se encuentran exentas del Tributo, en contra de lo previsto en el artículo 23 de la ley que grava las patentes comerciales. Es decir, la 
CGR infringiría el principio de legalidad y efectuaría una interpretación contra legem, en definitiva, se arrogaría potestades que no tiene.

La Corte ańade que la CGR, en los Dictámenes impugnados (No 27.677/2010, y No 6512/2012), abordaría materias que no son de su competencia legal, conforme las facultades que le otorgan la Constitución Política y su Ley Orgánica. La Corte indica que su perspectiva es coherente con la jurisprudencia del TC que ha seńalado que en el caso de conflicto por el pago de patentes comerciales, la competencia corresponde a los jueces de fondo, esto es, a los Tribunales Ordinarios de Justicia. A esto suma que los Tribunales Superiores de Justicia han determinado mediante innumerables sentencias ejecutoriadas, que se deben enterar en las arcas municipales los dineros correspondientes a patentes de sociedades de inversión.

Concluye la sentencia, afirmando que la CGR, mediante los dictámenes impugnados, ha afectado el derecho de propiedad de los municipios, al disponer la obligación de restituir los pagos efectuados por las sociedades de inversión desde 1 de julio de 2010, y al indicar que los ayuntamientos dejarán de percibir sumas similares a las ya ingresadas por patentes comerciales correspondientes a esas sociedades.

En virtud de todo lo afirmado, la Corte acoge el RP y deja sin efecto los Dictámenes impugnados.

\section{(2.2) SENTENCIA “CONTRALORÍA GENERAL CON MUNICIPALIDADES de Vitacura, ProVidencia, Macul y LA GRANJa II” (2012), DE LA CORTE SUPREMA ${ }^{16}$}

\section{(2.2.1) Introducción}

Esta sentencia, obtenida por tres votos contra dos, recae sobre un recurso de apelación del RP mencionado anteriormente, presentado por diversas municipalidades en contra de la interpretación que del D.L. $\mathrm{N}^{\circ}$ 3.063 (LRM), efectúa la CGR en el Dictamen $N^{\circ} 27.677$ de 25 de mayo de 2010, ratificado por el Dictamen $N^{\circ} 6.512$ de 1 de febrero de 2012. Esta sentencia aborda diferentes cuestiones relevantes y dignas de analizarse en profundidad, entre ellas, la configuración del impuesto local, la tutela jurisdiccional de la Caja Municipal, los derechos fundamentales de los órganos públicos, la sentencia judicial con valor de fuente formal del Derecho (i.e., norma jurídica de aplicación general).

16 Corte Suprema, 6 de noviembre de 2012, Rol No 5984-2012, "Contraloría General con Municipalidades de Vitacura, Providencia, Macul y La Granja II”, sentencia en apelación, Disponible en base de datos VLex: https://corte-suprema-justicia.vlex.cl/vid/ilustre-municipalidad-santiago-contralor-436095386 [Fecha de visita: 24 de abril de 2017] 


\section{(2.2.2) Hechos de la causa}

Esta sentencia -obtenida por mínima mayoría- básicamente se centra en defender las facultades de los Tribunales Ordinarios de Justicia para controlar la actuación de los órganos públicos, en general; y específicamente, en la posibilidad de desplegar dicho control vía RP. A partir de ello, sustenta la capacidad del órgano jurisdiccional de fiscalizar la actividad de la CGR - para lo cual levanta una teoría que justifique entender los dictámenes como actos administrativos-, y, luego, sostiene la existencia de derechos fundamentales de los órganos administrativos, y la posibilidad del RP de ser usado para proteger dichos derechos.

Un punto crucial del fallo se encuentra en el esfuerzo de restar jerarquía institucional a la CGR y fuerza normativa a sus decisiones e interpretaciones, y en elevar el valor de las sentencias judiciales (a las que individual o colectivamente las califica genéricamente como jurisprudencia) al nivel de Fuente Formal del Derecho, integrante del "bloque de legalidad" acoplada con la ley. Es decir, un pilar esencial de la tesis se articula sobre la defensa de alguna versión para nuestro sistema del "Derecho Jurisprudencial" o "Case Law". Sobre esa tesis busca justificar la calificación de "ilegal" que vierte sobre el dictamen impugnado de la CGR (lo que constituye una de las exigencias normativas para estimar un RP), porque no se sujetó dicho acto a las sentencias anteriores de la Corte Suprema.

De tributación dice poco, pero no por ello lo que sostiene es totalmente irrelevante.

Se revisará esta sentencia, a la luz de la de primera instancia, de otras sentencias sobre la materia, y de dictámenes de la CGR.

\section{(2.2.3) Decisión sobre el caso}

El fallo en comento considera ilegal el actuar de la CGR por vulnerar los artículos 23 y 24 de la LRM, evidentemente, la interpretación judicial de esos preceptos (y las adiciones que el Reglamento hace a la ley ${ }^{17}$ ). Para justificar la estimación del recurso presentado, la Corte afirma que el Dictamen impugnado ha vulnerado el derecho de propiedad de las Municipalidades sobre los tributos y multas que ya han percibido.

La decisión defiende el control judicial sobre la actuación de la CGR en términos generales, afirmando que corresponde a los tribunales de justicia verificar y ejercer el control de sus actos a través de las acciones que se interpongan, dado que la actuación de dicho órgano debe respetar la Constitución y la ley, y se encuentra sometida al principio de legalidad.

\footnotetext{
17 Decreto No 484 del Ministerio del Interior, de fecha 1 de agosto de 1980, que establece el "Reglamento para la Aplicación de los artículos 23 y siguientes del Título IV del DL. No 3.063, de 1979".
} 
En relación a la posibilidad concreta de efectuar este control vía RP, la sentencia afirma que los dictámenes de la CGR ("dictámenes o declaraciones de juicio", actos de naturaleza particular, de acuerdo a la Ley de Procedimiento Administrativo) son revisables por esta vía judicial, ya que constituyen actos administrativos (para lo que se apoya en la sentencia de la Corte Suprema de fecha 12 de enero de 2012, recaída en RP, autos Rol $\mathrm{N}^{\circ} 10.499-2011^{18}$ ). Agrega que esa es la naturaleza (y no la de circulares, que no crean Derecho) que presentan los dictámenes impugnados, pues "al resolver como lo hacen, constituyen actos administrativos que producen efectos jurídicos precisos obligando a la Municipalidad, y no emitiendo solamente una opinión sobre el alcance o interpretación que debe darse a un precepto legal”.

El fallo añade que el recurso de autos versa sobre un tema de Derecho Tributario, que constituye Derecho Administrativo Especial, y que el análisis de legalidad incluye tanto "las normas de Derecho Positivo como aquellos aspectos que constituyen la base del derecho administrativo, como es el caso de la jurisprudencia" judicial; y en tales términos la CGR debe "inclinarse frente a la jurisprudencia de los tribunales, lo que es fundamental para el orden institucional", lo que es particularmente válido cuando esta es uniforme ${ }^{19}$, ya que la jurisprudencia judicial, constituye "fuente del Derecho Administrativo", por lo que si las sentencias de la Corte Suprema decretan que "las sociedades de inversión deben pagar patente municipal" este criterio constituye "fuente del derecho y como tal integra el denominado bloque de la legalidad", siendo obligatorio para la CGR.

\section{(2.2.4) Análisis de la vía procesal}

Como se ha indicado, esta sentencia se logró en decisión dividida, de mayoría, de tres votos contra dos, lo que constituye el primer obstáculo para considerarla como una pieza relevante desde una perspectiva institucional. Con todo, debe tenerse presente la existencia de otras sentencias

18 Fallo de primera instancia: Corte de apelaciones de Iquique, Rol No 452-2011 Civil (Protección), sentencia de 21 de octubre de 2011. Las sentencias de ambas instancias desestimaron el RP.

19 Nótese que una dificultad precisa para analizar sentencias y compararlas con otras semejantes, está constituida por las notas especiales del caso. Por ejemplo, dado el argumento vertido por la Corte Suprema en el sentido de que el objeto social determina el pago de patente, en algunos casos concretos el contribuyente integra en el giro social actividades de servicio o de manufactura; y en otros casos, no. Esta clase de distinciones, entre las múltiples que deben considerarse en el contexto de la defensa del "Derecho Jurisprudencial" o "Case Law" efectuado, no se encuentran en las sentencias de la Corte Suprema, y resultan relevantes (noción expuesta en Cross y HARris 2012, 23). Ver también sentencia de la Corte Suprema, recurso de protección, estimatorio, Municipalidad de Zapallar contra Dictamen de la Contraloría Regional de Valparaíso, que la obligaba a reintegrar dineros ingresados por el cobro de patente municipal a una sociedad de inversión, 3 de julio de 2012, causa Rol No 2791-2012. 
en sentido semejante, obtenidas con la concurrencia de un mayor número de magistrados.

Otra limitación se encuentra en el proceso mismo en que fue obtenida. El RP da lugar a un proceso de naturaleza cautelar, de emergencia y de resultado provisional, entre otras peculiaridades. No da lugar a un litigio propiamente tal, y tampoco un procedimiento legalmente reglado con etapas que permitan conducir adecuadamente un debate jurídico que produzca un pronunciamiento acerca del fondo de un asunto (solo se han instituido pautas procesales generales mediante un auto acordado).

En cuanto al fondo, las posturas que defiende esta decisión de mayoría también muestran debilidad desde una perspectiva argumental y dogmática. Esto deberá abordarse, aún sucintamente. Con todo, lo que ha conducido a llevar a cabo esta publicación es el análisis de los aspectos vinculados a la dogmática y la justicia en el ámbito tributario.

Respecto de los aspectos de Derecho Procesal Constitucional y Derecho Administrativo, no resulta posible compartir la postura de la mayoría:

(a) La sentencia reitera (amparada en precedentes judiciales, sentencia de Corte Suprema Rol N²791-2012) que las Municipalidades constituyen "sujetos titulares de Derechos Fundamentales", y en cuanto tales, tienen legitimación activa para interponer el RP. Cabe hacer notar que si bien el RP constituye una institución que no presenta perfiles jurídicos definidos, lo que permite que desde cierta perspectiva sea considerado como un mecanismo de control judicial de la legalidad del acto administrativo, de ello no es posible derivar que dicho control implica la titularidad de derechos fundamentales de los órganos públicos.

(b) Si bien la propia norma constitucional que consagra el RP prescribe que son los actos ilegales y arbitrarios los que en virtud de ella resultan impugnables, no es posible sostener que el Dictamen $\mathrm{N}^{\circ}$ 6.512/2012 y el Dictamen $\mathrm{N}^{\circ} 27.677 / 2010$, de la CGR, presentan tales perfiles de ilicitud en cualquiera de los sentidos indicados.

(c) Esto nos conduce al siguiente punto. A nuestro parecer, la CGR al dictar esos actos, ha actuado en la esfera de sus atribuciones legales (específicamente de acuerdo al artículo $6^{\circ}$ de su Ley Orgánica), y en razón de ello, un procedimiento cautelar de naturaleza sumaria (de urgencia) como es el $\mathrm{RP}$ no puede ser defendido como un procedimiento adecuado para ventilar esta clase de asuntos. Correspondería acudir a un contradictorio de lato conocimiento, que es el camino diseñado en nuestro ordenamiento jurídico dada la inexistencia de tribunales y procedimientos administrativos especializados. Pero aún en tal caso, no debiera ser judicializable la interpretación general que efectúa la CGR mediante dichas atribuciones legales. Existen buenas razones por las cuales no debe litigarse en contra de interpretaciones 
administrativas de carácter general en ejercicio de atribuciones otorgadas por ley, idea que ya ha sido plasmada en nuestro ordenamiento, por ejemplo, en el caso de circulares y resoluciones del SII (nótese que de modo aún más general regula esto el Código Tributario en su artículo 126). Otro enfoque rompe con el reparto institucional de potestades públicas. Cualquier orden institucional fundado en reglas (como es el caso de un Estado de Derecho) implica límites. La actividad judicial también debe estar sometida a límites, en todos los casos y aun en caso de procedimientos auténticos de tutela de derechos fundamentales (como no lo es propiamente el RP).

(d) Se ha defendido por algunos que el RP, al tratarse de una acción de origen constitucional de tutela de derechos fundamentales, da origen a una potestad judicial ilimitada en forma (mecanismos) y fondo (contenido de las sentencias). La práctica jurídica nacional ha hecho que se tutela aquel derecho que se comprende más fácilmente, cual es, el derecho de propiedad, lo que ha derivado en una hipertrofia de este mediante la construcción del derecho de propiedad sobre los derechos y sobre las posiciones jurídicas e intereses. La propietarización de los derechos ha tornado inútil la preocupación dogmática o judicial relativa a cualquier otro derecho fundamental. Con el derecho de propiedad se intentan resolver todos los conflictos, para en el fondo no dejar nada resuelto en términos propiamente jurídicos (y no meramente autoritativos). Esto es lo que sucede en este caso, como intentaremos mostrar.

El fundamento teórico que se encuentra en la raíz de mecanismos como el RP (y que por diversas causas fracasan) es que se busca tutelar el "derecho fundamental" entendido como expresión jurídicamente definida y configurada del "derecho humano", siendo este último un parámetro moral que debe guiar tanto la actuación de personas físicas o jurídicas como la de los órganos públicos. Este parámetro moral -el derecho humano- debe iluminar tanto la generación de la ley como la práctica judicial y administrativa, a través de las vías institucionales de un Estado de Derecho, calificativo posible de aplicar a nuestro sistema jurídico.

La confusión que en general se ha ocasionado, entonces, radica en que el RP sirve para defender cualquier posición jurídica o interés (aún sin existencia de derecho) a través de cualquier modo (que en cada caso lo define libremente el sentenciador). Y ello no puede ser correcto, precisamente porque rompe el sistema institucional, al transformar la función jurisdiccional en un poder ilimitado. Es en tal escenario que emerge la defensa (de alguna versión) del "Case Law" o del "Derecho Jurisdiccional", o del Juez-Legislador.

De lo anterior es que resulta necesario volver a reflexionar acerca de la estructura del RP, para configurarlo como un mecanismo cautelar, sumario y provisional dentro de procedimientos claramente institucionales, definiendo su procedimiento, los alcances de las resoluciones que respecto de él 
se produzcan, su legitimación activa y pasiva, etc. Asimismo, debe exigirse que en la defensa de cada situación jurídica se demande la defensa de un derecho fundamental específico y delimitado, evitando que se recurra o en la demanda o en la sentencia al derecho de propiedad de derechos, sino específica y perfiladamente al derecho preciso que se alega ha sido vulnerado.

(e) El RP constituye un procedimiento cautelar de naturaleza sumaria, de emergencia, y por ello, se ha dicho, no es susceptible de generar cosa juzgada material, pues no resuelve sobre el fondo del asunto, dejando a salvo la posibilidad de ventilar los mismos asuntos litigiosos mediante los procedimientos pertinentes. Si es así (la estructura normativa del RP efectivamente permite sostener ello), no es posible afirmar que las sentencias que este mecanismo produce generan "jurisprudencia”, en el sentido de precedentes (normas) jurídicamente vinculantes o Fuentes del Derecho.

(f) En el ordenamiento jurídico chileno, la "jurisprudencia” o el precedente judicial no constituye Fuente Formal del Derecho, en otros términos, las sentencias (aunque exista cierta uniformidad en sentencias de determinado órgano jurisdiccional) no obligan a los órganos públicos o a los particulares o a otros tribunales sino solo a las partes del proceso en que se dictó, es decir, solo vincula en el caso concreto (por cierto que obliga a terceros a respetar el contenido de esa sentencia). Es posible que la pretensión del voto de mayoría, que formó la sentencia comentada, sea consecuencia de la influencia constitucional de otros países, en los cuales existe la institución legal y/o constitucionalmente consagrada de la "interpretación conforme a la Constitución” fijada por el "máximo intérprete de la Constitución". Por muy atractiva que resulte esta institución, esta no ha sido establecida en Chile y no constituye parte de las atribuciones de la Corte Suprema o de las Cortes de Apelaciones.

(g) Dado lo anterior, no puede estimarse como vinculante para la CGR los fallos de la Corte Suprema de un modo general o genérico, ya que dicho órgano judicial no es su superior jerárquico, ni puede (al menos amparada en norma reconocida en nuestro sistema jurídico) dictar órdenes generales a dicha institución en el marco del ejercicio de las funciones legalmente consagradas y atribuidas a la Contraloría.

No se trata de defender una supuesta intangibilidad o infalibilidad de las decisiones de la CGR, ya que cualquier practicante experimentado habrá podido detectar errores jurídicos en más de una decisión o interpretación de dicho organismo. Reconocemos en tales casos la extrema importancia del papel de los órganos jurisdiccionales. Lo que yerra en este caso concreto es en el mecanismo (un RP) y en los argumentos vertidos para estimarlo. 
Por lo anterior, el autor de este artículo se acerca a la postura del voto de minoría, al menos parcialmente, y no en lo referido a una supuesta autonomía institucional de la CGR que la dejaría fuera de cualquier control judicial. Pero por cierto, si institucionalmente existe un órgano público que fiscaliza el actuar de otros, ellos debieran institucionalmente someterse a aquel.

Los dos ministros disidentes estuvieron por revocar la sentencia apelada, rechazando el RP interpuesto, dado que la actividad financiera de las Municipalidades (reguladas por la Ley No 18.695 Orgánica Constitucional) se encuentra sujeta a la fiscalización de la CGR, de acuerdo al artículo 1 de la Ley $\mathrm{N}^{\circ} 10.336$ orgánica de la $\mathrm{CGR}^{20}$ y el artículo 52 de la Ley $\mathrm{N}^{\circ}$ 18.695. Los disidentes agregaron que la potestad de emitir dictámenes de la CGR emana del artículo 98 constitucional, y de los artículos 5, 6 y 9 de la Ley $\mathrm{N}^{\circ} 10.336$, dado que dicha norma constitucional encomienda a la CGR, en cuanto órgano autónomo, entre otras materias, ejercer el control de legalidad de los actos administrativos, fiscalizar el ingreso y la inversión de los fondos del Fisco y las Municipalidades. Dichos dictámenes configuran la jurisprudencia administrativa y es obligatoria para las entidades sujeta a su fiscalización. Dadas dicha vinculación y dependencia de las Municipalidades hacia la CGR, las primeras carecen de legitimidad activa para recurrir de protección para impugnar una determinada interpretación materializada en un dictamen, cuando este tiene carácter general, ello no solo porque está realizada por el órgano llamado a hacerlo, sino porque, una vez hecha ella es obligatoria para las Municipalidades. Entenderlo de otra manera, ańaden, hace que el RP se convierta en una vía para que una Municipalidad se alce en contra de su legítimo órgano de control, en materias que escapan a una legítima discrepancia, introduciéndose un elemento de inestabilidad en el sistema de administración comunal. Por lo demás, existen otras vías idóneas para resolver este tipo de conflictos.

\section{(2.2.5) Comentario}

Los sentenciadores hacen escasas referencias a asuntos de naturaleza tributaria. Básicamente dedican su esfuerzo en defender dos aristas: una muy amplia potestad de revisión judicial de los actos administrativos; el carácter de la sentencia judicial como fuente formal del Derecho, a través de la figura del "bloque de legalidad" en el cual la sentencia se integra con la ley, otorgándole a la sentencia un efecto general o una aplicación general (aunque no explica en qué casos opera esto, es decir, frente a cada sentencia o a un grupo de sentencias; no resuelve los casos de sentencias divergentes; o los casos de sentencias de diversos procedimientos,

20 Ley $N^{\circ}$ 10.336, Ley de Organización y Atribuciones de la Contraloría General de la Republica, de 29 de mayo de 1952. 
o de tribunales de diversa jerarquía, o sentencias unánimes o con voto mayoritario; etc. $)^{21}$.

Debe recordarse que el contexto de esta decisión judicial está constituida por un RP (consagrado en el artículo 20 constitucional) presentado para "amparar el legítimo ejercicio de las garantías y derechos" de la caja presupuestaria de importantes Municipalidades (i.e., de la propiedad sobre dineros recaudados a título de tributos), y que dicha acción cautelar se dirige en contra del actuar de la CGR, concretado en la emisión de su Dictamen $N^{\circ} 6.512 / 2012$, por el cual desestimó las reconsideraciones planteadas contra su anterior Dictamen $N^{\circ} 27.677 / 2010$. En lo sustancial, los recurrentes cuestionan la opinión de la CGR en cuanto a que no procedía el cobro de patente municipal a las sociedades de inversión pasiva por no desarrollar una actividad lucrativa en los términos que exige la LRM, al no configurar el hecho gravado contemplado en su artículo 23, en aplicación del principio de reserva legal en materia tributaria.

En relación a las cuestiones de carácter tributario, es posible referirse a tres asuntos: el principio de reserva de ley; el principio de legalidad; la construcción y aplicación del tributo conforme a criterios constitucionales de justicia tributaria (específicamente, de capacidad contributiva).

\section{(2.2.6) La sentencia a la luz de principios de la tributación}

El hecho gravado del impuesto local exige que se trate de una actividad lucrativa primaria o extractiva en los casos de explotaciones en que medie algún proceso de elaboración de productos y los productos se vendan por los productores; y actividades lucrativas secundarias (manufacturas) y terciarias (servicios). De modo genérico, la ley impone el gravamen sobre "el ejercicio de toda profesión, oficio, industria, comercio, arte o cualquier otra actividad lucrativa secundaria o terciaria, sea cual fuere su naturaleza o denominación".

La patente grava la actividad que se ejerce con prescindencia de la clase o número de giros o rubros distintos que comprenda.

Tratándose de sociedades de inversiones o sociedades de profesionales, cuando estas no registren domicilio comercial, la patente se deberá pagar en la comuna correspondiente al domicilio registrado por el contri-

21 Ahora, el fallo no discurre acerca de los supuestos en que existen sentencias (individuales) en sentido contrario; o grupos de sentencias en sentido divergente; o si una o dos sentencias concordantes constituyen Fuente Formal del Derecho con independencia o dependencia de otros factores o consideraciones; o si una o más sentencias obligan al mismo Tribunal o a otros jueces acerca de ese punto de derecho, o a jueces inferiores; o si debe diferenciarse entre sentencias logradas por mayoría o unánimemente; o acerca de la autoridad jurídica del magistrado que vota a favor de la sentencia o del voto disidente; etc. Toda esta clase de aspectos son relevantes o al menos no debieran ser considerados como irrelevantes o indiferentes al momento de analizar las sentencias. (Cross y Harris, 2012) 109 y ss. 
buyente ante el SII. La LRM establece que el Presidente de la República reglamentará la aplicación de los artículos 23 y 24 de la LRM.

Dicho lo anterior, debe recordarse que lo que se rechaza por parte de los contribuyentes es que deban pagarse impuestos locales por inversiones de carácter pasivo.

Respecto del impuesto local, la CGR establece unas exigencias para su aplicación:

a) Que la actividad se encuentre legalmente gravada con ese tributo;

b) Que esta sea efectivamente ejercida por el contribuyente;

c) Que la actividad se realice en un local, oficina, establecimiento, quiosco o lugar determinado.

Para la CGR, la "inversión pasiva" consiste, en general, en la adquisición de toda clase de bienes con fines rentísticos, sea cual fuere la forma jurídica que adquiera el inversionista, que no involucre la producción de bienes ni la prestación de servicios. Ello no constituiría un hecho gravado de acuerdo al artículo 23 del D.L. N³.063 de 1979.

La CGR ańade que el requisito vinculado al desarrollo efectivo de una actividad gravada no se cumple con la sola consideración del objeto social especificado en los estatutos de la sociedad, sino que se requiere que tal ejercicio se encuentre acreditado y sea efectivo, debiendo el Municipio ponderar los antecedentes aportados por el interesado y los que recabe por sus propios procedimientos de inspección para tales efectos.

En caso de que la Municipalidad haya percibido ingresos a título de tributos y multas en contra de la interpretación de la CGR, estos deben ser reintegrados al contribuyente.

Para la Corte Suprema (particularmente en la sentencia comentada), una sociedad es sujeto pasivo de patente municipal si "la actividad que realiza" está comprendida dentro del hecho gravado definido en la ley "en atención al objeto social" de ella. De ese modo, "si el objeto social incorpora, contiene, describe o permite la realización de actividades lucrativas, configuran estas hechos gravados de acuerdo con lo previsto en el artículo 23 de la Ley de Rentas Municipales".

El artículo 23 de la LRM (D.L. $N^{\circ}$ 3.063) sujeta a contribución de patente municipal "El ejercicio de toda profesión, oficio, industria, comercio, arte o cualquier otra actividad lucrativa secundaria o terciaria"; y el art $2^{\circ}$ del D.S. $N^{\circ} 484$ que reglamenta la aplicación de los artículos 23 y 24 de la LRM, actividades terciarias son todas aquellas que consisten en el comercio y distribución de bienes y en la prestación de servicios de todo tipo $y$, en general, toda actividad lucrativa que no quede comprendida en las primarias y secundarias. Para la sentencia, se trata de un "concepto amplio y residual de la actividad terciaria" dentro de las cuales se comprenden las actividades lucrativas realizadas por las sociedades de inversión. 
A continuación, la sentencia añade que "no es acertado estimar que si no hay ejercicio efectivo de tales actividades no se debe pagar patente municipal, desde que este gravamen es semestral y habilita para desarrollar las actividades a que se refiere el artículo 23 del D.L. $\mathrm{N}^{\circ} 3.063$, sin que se requiera el ejercicio efectivo. De acogerse la tesis contraria resultaría que procedería pagar una patente proporcional a la época en que se realizó alguna actividad, lo que por cierto es insostenible."

No podemos concordar con que: (a) La jurisprudencia o las decisiones judiciales puedan completar una norma tributaria, en el sentido de incorporar uno de los elementos esenciales del tributo; (b) Un Decreto pueda completar una norma tributaria, en el mismo sentido. En ambos casos se viola el principio de reserva de ley en el ámbito tributario, que está constitucionalmente consagrado.

La perspectiva de la sentencia judicial comentada es argumentalmente contradictorio y dogmáticamente cuestionable.

La sentencia fracasa en la articulación de su argumento. Que un determinado giro o actividad gravable formalmente se encuentre mencionado en el objeto de la sociedad no significa que "la actividad se realiza".

Desde una perspectiva dogmática, se vulnera el principio de capacidad contributiva, pues no nos encontramos frente a riquezas reales, y a nuestro juicio, tampoco de carácter potencial, sino meramente ficticios o nominales, los que no pueden constituir el fundamento material del tributo, entendida como categoría universal (como lo planteó la sentencia del Tribunal Constitucional español 37/1987). Como ha planteado la doctrina, dicho principio constituye un presupuesto y un límite del tributo, en los términos indicados. Establecer tributos u obligar a tributar sin consideración a la capacidad contributiva arrasa contra la racionalidad mínima sobre la que se debe construir el sistema tributario ${ }^{22}$.

Finalmente, desde la perspectiva del principio de legalidad, al que debe sujetarse el órgano recaudador, se vulnera este principio si no se sujeta a la ley tributaria (la LRM, en este caso), que debe interpretarse en sentido estricto (entre otras razones, por establecer potestades y por limitar derechos fundamentales del contribuyente), y por no sujetarse a las normas legales que regulan la fiscalización de los organismos recaudadores (la Ley Orgánica de la CGR).

Esta sentencia gira en torno a la idea de tutelar los derechos fundamentales del órgano recaudador de tributos (Municipalidades), y no justifica (y estimamos que es imposible de justificar) de qué modo las Municipalidades (o su Caja) pueden gozar de derechos fundamentales (los que constituyen una expresión jurídica de los derechos humanos). Al contrario, omite todo pronunciamiento acerca de las categorías esenciales

22 Romero (2005) 217. En nuestro medio, Massone (2013) 126 y ss., justifica dicho principio como una exigencia propia del tributo en el Derecho Comparado. 
sobre las cuales se sustenta y fundamenta el tributo y la obligación tributaria. La capacidad económica, principio que exige la determinación fiscal de una riqueza efectiva sobre la cual aplicar el gravamen, constituye por un lado un fundamento y un límite de la carga tributaria a que se somete a un contribuyente; y a su vez constituye un derecho fundamental, en el sentido de que si se detrae por el Fisco más allá de la porción que legítimamente (no legalmente, pues puede haber leyes inconstitucionales) corresponde, se produce un atentado contra el derecho de propiedad del contribuyente, una vulneración al principio tributario de no confiscatoriedad.

\section{(2.2.7) Discusión exegética}

Por otra parte, este Tribunal ha sostenido que no es acertado estimar que si no hay ejercicio efectivo de tales actividades no se debe pagar patente municipal, desde que este gravamen es semestral y habilita para desarrollar las actividades a que se refiere el artículo 23 de la LRM, sin que se requiera el ejercicio efectivo. De acogerse la tesis contraria resultaría que procedería pagar una patente proporcional a la época en que se realizó alguna actividad, lo que por cierto es insostenible.

\section{(3) LA POSTURA EXPRESADA EN LAS SENTENCIAS DEL TRIBUNAL CONSTITUCIONAL}

La postura adoptada por el Tribunal Constitucional ha favorecido la postura de la Corte Suprema (y Cortes de Apelaciones, en general) y de las Municipalidades. Es posible distinguir dos etapas, desde 2008 a 2012, y desde 2012, con un cierre definitivo de este debate a través de varias sentencias de 2013. La bisagra la podríamos ubicar en la sentencia 13.090-2010. Los casos concretos y su respectivo desenlace fueron los siguientes:

\section{(3.1) Sentencia Recaída en aUtos Rol No 1242-2008, de 9 DE OCTUBRE DE $2008^{23}$}

En esta sentencia se declaró inadmisible el requerimiento de inaplicabilidad por inconstitucionalidad de los artículos 23 y 24 de la LRM, dado que el Tribunal estimó que lo que perseguía el contribuyente era

23 Tribunal Constitucional, Rol No 1242-2008, de 9 de octubre de 2008, Requerimiento de inaplicabilidad deducido por Inversiones Las Perdices Limitada respecto de los artículos 23 y 24 del DL No 3063 -Ley de Rentas Municipales-, en causa Rol No 3909/2008 de la Corte de Apelaciones de Santiago. Disponible en: http://www.tribunalconstitucional.cl/sentencias/busqueda-basica [Fecha de visita: 24 de abril de 2017]. 
una determinada interpretación de la ley, y el asunto planteado constituía una cuestión de legalidad cuya resolución era propia de los jueces del fondo 24 .

\section{(3.2) SENTENCIA RECAÍdA EN AUTOS Rol No 1256-2008, DE 22 DE OCTUBRE DE 2008 25}

Se declaró inadmisible el requerimiento de inaplicabilidad por inconstitucionalidad de los artículos 23 y 24 de la LRM, dado que el Tribunal estimó que no contenía una impugnación razonablemente fundada. El recurrente buscaba un pronunciamiento acerca del verdadero sentido y alcance de las expresiones "actividad primaria, secundaria y terciaria" a que aluden los preceptos legales impugnados, y con ello se le planteó al TC una cuestión de interpretación legal que no quedaba comprendida dentro de sus atribuciones. Hay un voto disidente del Ministro señor Mario Fernández Baeza, quien estimaba pertinente declarar la admisibilidad de la acción, razonando con fundamentos sobre la posible consecuencia de resultados contrarios a la Constitución que acarrearía la aplicación en este caso del artículo 23 de la LRM, al vulnerarse el artículo 65 No 1 , en relación al artículo 63 No 14 constitucionales, que consagran la legalidad de los tributos. En el voto se sostiene que las expresiones "actividades lucrativas secundarias y terciarias", así como las "actividades primarias o extractivas" utilizadas en la ley, presentan un significado impreciso y ajeno al uso actual del lenguaje usual. Agrega que actualmente se habla de "industria" para describir a todas las actividades, incluyendo a aquéllas propias de los servicios -antes llamada terciaria- y otras más difíciles de encasillar en la tríada clásica - primaria, secundaria y terciaria, como son, entre otras, las actividades de las comunicaciones, denominadas hoy como "industria medial". En consecuencia, la ley no resulta clara para distinguir entre las actividades que se gravan y, por ello, su aplicación puede resultar contraria a la Constitución.

24 El Ministro Jorge Correa Sutil ha señalado (en sentencia de 24 de enero de 2008, causa Rol No 810-2007) que el TC uniformemente ha sostenido que es posible entender en más de un sentido un precepto legal, pudiendo ser algunas interpretaciones contrarias a la Constitución. Por ello, en algunas sentencias recaídas en acciones de inaplicabilidad ha prohibido aplicar un precepto legal con un determinado alcance o sentido que resultaría contrario a la Constitución o ha permitido su aplicación en el entendido de que será aplicada de un modo determinado, como ha sucedido en las sentencias de 31 de agosto de 2007 (causa Rol No 747), 29 de noviembre de 2007 (causa Rol No 736) y 11 de diciembre de 2007 (causa Rol No 806).

25 Tribunal Constitucional, Rol No 1256-2008, de 30 de octubre de 2008, Requerimiento de inaplicabilidad de Inversiones Integradas S.A. respecto de los artículos 23 y 24 del Decreto Ley No 3.063, en causa Rol No 6799-2007 de la Corte Suprema. Disponible en: http://www.tribunalconstitucional.cl/sentencias/busqueda-basica [Fecha de visita: 24 de abril de 2017]. 


\section{(3.3) SENTENCIA ReCAÍdA EN AUtos Rol No 1453-09-INA, 20 DE JULIO DE 2010}

En esta causa, el requirente planteó que se vulneraba el derecho de reserva de ley en materia tributaria, propiedad -por gravar el patrimonio y no la renta- e igualdad en materia tributaria. El Tribunal rechazó por improcedente el requerimiento de inaplicabilidad por inconstitucionalidad de los artículos 23 y 24 de la LRM presentado, pues estimó que lo que perseguía el contribuyente con su requerimiento era la obtención de una interpretación de las normas referidas, las que calificaba de obscuras e imprecisas, no planteando entonces un conflicto de constitucionalidad que se encontrara dentro de la esfera de competencias del $\mathrm{TC}^{26 .}$

\section{(3.4) SENTENCIA ReCAÍdA EN aUtos Rol No 1454-09-INA, 20 DE JULIO DE $2010^{27}$}

El TC negó lugar al requerimiento de inaplicabilidad por inconstitucionalidad de los artículos 23 y 24 de la LRM, por las mismas razones entregadas en la STC Rol 1453-09-INA.

\section{(3.5) SENTENCIA RECAÍdA EN AUtOS Rol No 1724-10-INA, 15 DE JUNIO DE $2010^{28}$}

Se declaró inadmisible el requerimiento de inaplicabilidad por inconstitucionalidad de los artículos 23 y 24 de la LRM. Como en an-

26 Tribunal Constitucional, Rol No 1453-09-INA, 20 de julio de 2010, Requerimiento de inaplicabilidad por inconstitucionalidad de Sociedad Inversiones Las Lilas Dos Limitada respecto de los artículos 23 y 24 del Decreto Ley No 3.063, de 1979 -sobre Rentas Municipales-, en los autos Rol No 3606-2009, sobre el recurso de casación en el fondo interpuesto ante la Corte Suprema en contra del fallo de la Corte de Apelaciones de Santiago que rechazó el reclamo de ilegalidad municipal deducido en contra del cobro de patente que ha dispuesto la Municipalidad de Providencia. Disponible en: http://www.tribunalconstitucional. cl/sentencias/busqueda-basica [Fecha de visita: 24 de abril de 2017]

27 Tribunal Constitucional, Rol No 1454-09-INA, 20 de julio de 2010, Requerimiento de inaplicabilidad por inconstitucionalidad de sociedad Inmobiliaria Lomas de Quelén S.A. respecto de los artículos 23 y 24 del Decreto Ley No 3.063, de 1979 -sobre Rentas Municipales-, en los autos Rol No 2210-2009, sobre recurso de casación en el fondo interpuesto ante la Corte Suprema en contra del fallo de la Corte de Apelaciones de Santiago que rechazó el reclamo de ilegalidad municipal deducido en contra del cobro de patente que ha dispuesto la Municipalidad de Santiago respecto de la referida sociedad. Disponible en: http://www. tribunalconstitucional.cl/sentencias/busqueda-basica [Fecha de visita: 24 de abril de 2017]

Tribunal Constitucional, Rol No 1724-10-INA, 15 de junio de 2010, Acción de inaplicabilidad por inconstitucionalidad de Inversiones Deportivas Vińa del Mar S.A. respecto de los artículos 23 y 24 del Decreto Ley No 3063, de 1979, sobre Rentas Municipales, en los autos Rol No 1677-2009 sobre reclamo de ilegalidad interpuesto ante la Corte de Apelaciones de Valparaíso en contra de la I. Municipalidad de Valparaíso. Disponible en: http://www. tribunalconstitucional.cl/sentencias/busqueda-basica [Fecha de visita: 24 de abril de 2017] 
teriores casos, el contribuyente solo perseguía del TC una determinada interpretación de la ley -lo que corresponde decidir a los Tribunales Ordinarios-, no planteando un auténtico conflicto de constitucionalidad.

\section{(3.6) SENTENCIA RECAÍdA EN AUTOS Rol No 1.873-10-INA, 25 DE AGOSTO DE $2011^{29}$}

Se acoge el requerimiento solo en cuanto se declara inaplicable, en la gestión judicial pertinente, el precepto contenido en el artículo 768 inciso $2^{\circ}$ del Código de Procedimiento Civil. Si bien el litigio traía causa en el cobro de patente municipal, terminó alegándose por el contribuyente los derechos del debido proceso y la tutela judicial efectiva ante el TC. Acordada con dos votos en contra (del Ministro Francisco Fernández; de los Ministros Carlos Carmona, José Antonio Viera-Gallo y Gonzalo García). Esta decisión recae en la causa Inversiones Rotondo Limitada contra I. Municipalidad de Las Condes.

\section{(3.7) SENTENCIA RECAÍdA EN AUTOS Rol No 1.390-09-INA, 8 DE ABRIL DE 2010 30}

En esta sentencia (desestimatoria) resuelve que se trata de una cuestión de mera legalidad, consistente en determinar si el sentido y alcance de los artículos 23 y 24 del decreto ley No 3063 (C 15\%), es decir, de las interpretaciones posibles de una ley $\left(\mathrm{C} 14^{\circ}\right)$, y que entonces tiene su procedimiento específico ante la Corte de Apelaciones y ante la Corte Suprema (casación). La primera ya resolvió en orden a que la sociedad requirente está afecta al pago de patente municipal $\left(\mathrm{C} 16^{\circ}\right)$. Finalmente, a juicio del TC "del examen concreto de lo sostenido en autos, esta Magistratura tampoco desprende sustento alguno para apoyar el demérito constitucional, formal ni sustantivo, de ninguno de los cuatro preceptos legales mencionados, aisladamente evaluados" (C 17\%).

29 Tribunal Constitucional, Rol No 1873-10-INA, 25 de agosto de 2011, Requerimiento de inaplicabilidad por inconstitucionalidad presentado por Inversiones Rotondo Limitada respecto del inciso segundo del artículo 768 del Código de Procedimiento Civil, en los autos Rol No 8583-2009 sobre reclamo de ilegalidad interpuesto ante la Corte de Apelaciones de Santiago en contra de Municipalidad de Las Condes. Disponible en: http://www.tribunalconstitucional.cl/sentencias/busqueda-basica [Fecha de visita: 24 de abril de 2017]

Tribunal Constitucional, Rol No 1390-09-INA, 8 de abril de 2010, Requerimiento de inaplicabilidad por inconstitucionalidad de Inversiones San Lorenzo Internacional S.A., respecto del artículo $1^{\circ}$ inciso $2^{\circ}$ de la Ley 18.046, en Rol No 5916-2008 de la Corte Suprema. Disponible en: http://www.tribunalconstitucional.cl/sentencias/busqueda-basica [Fecha de visita: 24 de abril de 2017] 


\section{(3.8) SENTENCIAS RECAÍdAS EN aUtos Roles $\mathrm{N}^{\circ}$ 2104-11-INA, $\mathrm{N}^{\circ}$ 2135-11-INA, N $^{\circ}$ 2134-11-INA, $N^{\circ}$ 2141-11-INA}

El TC resuelve una serie de causas semejantes, el día 14 de marzo de 2013, mediante sentencias recaída en autos roles $\mathrm{N}^{\circ}$ 2104-11-INA, STC Rol N ${ }^{\circ}$ 2135-11-INA, STC Rol No 2134-11-INA, STC Rol N ${ }^{\circ}$ 2141-11-INA ${ }^{31}$. Todas estas sentencias desestiman las pretensiones de los requirentes, sustentando que no se vulneran los principios de reserva de ley tributaria ni de igualdad. La STC Rol No 2104-11-INA, no considera vulnerado el principio de reserva de ley dado que a su parecer la ley establece adecuadamente los elementos esenciales del tributo, no existiendo márgenes de indeterminación normativa, para lo que se apoya, a su vez, en sentencias de la Corte Suprema (sentencia de dicha Corte, Rol $\mathrm{N}^{\circ}$ 2791-2012) y en dictámenes (en fase de reconsideración) de la CGR (Dictamen $\mathrm{N}^{\circ}$ 71.250/2012). Asimismo, señala que el procedimiento para resolver esta cuestión en nuestro ordenamiento jurídico, es el recurso de casación en el fondo ante la Corte Suprema (STC Rol N ${ }^{\circ} 1390-2010$, C $16^{\circ}$ y C $\left.17^{\circ}\right)$. Agrega que (C 18\%) "el test esencial a verificar es si el desarrollo normativo del legislador ha sido sobrepasado en la colaboración reglamentaria. Por tanto, hay que verificar si concurre en este caso la regla de determinación y especificidad de la obligación tributaria (STC Rol $\mathrm{N}^{\circ} 465, \mathrm{C} 25^{\circ}$ ). El argumento que concluye con la determinación de un tributo es que este sea específico en la afectación de los derechos fun-

31 Detalles de estos casos son los siguientes:

- Tribunal Constitucional, Rol No 2141-11 Requerimiento de inaplicabilidad por inconstitucionalidad presentado por Inversiones Luma Limitada respecto de los artículos 23, inciso tercero, y 24, inciso primero, ambos del Decreto Ley $\mathrm{N}^{\circ} 3.063$, Ley sobre Rentas Municipales, en los autos sobre recurso de casación en el fondo caratulados "Inversiones Luma Limitada con De la Maza Chadwick Francisco", de que conoce la Corte Suprema, bajo el Rol N 10.268-2011.

- Tribunal Constitucional, Rol No 2134-11 Requerimiento de inaplicabilidad por inconstitucionalidad presentado por Inversiones Mañío Limitada respecto de los artículos 23, inciso tercero, y 24, inciso primero, ambos del Decreto Ley $\mathrm{N}^{\circ} 3.063$, Ley sobre Rentas Municipales, en los autos sobre reclamo de ilegalidad caratulados "Inversiones Mañío Limitada con I. Municipalidad de Las Condes", de que conoce la Corte de Apelaciones de Santiago, bajo el Rol N 1414-2010, en actual casación en el fondo ante la Corte Suprema.

- Tribunal Constitucional, Rol No 2135-11 Requerimiento de inaplicabilidad por inconstitucionalidad presentado por Inversiones Lingue Limitada respecto del artículo 23, inciso tercero, del Decreto Ley $\mathrm{N}^{\circ}$ 3.063, Ley sobre Rentas Municipales, en los autos sobre reclamo de ilegalidad caratulados "Inversiones Lingue Limitada con I. Municipalidad de Las Condes", de que conoce la Corte de Apelaciones de Santiago, bajo el Rol N 1416-2010, en actual casación en el fondo ante la Corte Suprema.

- Tribunal Constitucional, Rol No 2104-11 Requerimiento de inaplicabilidad por inconstitucionalidad presentado por Inversiones MC \& MC II Limitada respecto de los artículos 23, inciso tercero y 24, inciso primero, ambos del Decreto Ley $\mathrm{N}^{\circ} 3063$, Ley sobre Rentas Municipales, en los autos sobre reclamo de ilegalidad caratulados "Inversiones MC \& MC II Limitada con Ilustre Municipalidad de Las Condes”, de que conoce la Corte de Apelaciones de Santiago, bajo el Rol Nº1.412-2010. 
damentales involucrados y que aquello se realice por ley adecuadamente ejecutada por normas reglamentarias". Ahora, (C 19'), el TC afirma que el artículo 23, inciso 3o del D.L N³.063 "no es más que la aplicación de la potestad reglamentaria de ejecución de la ley que todo cuerpo legal envuelve", reconocido en el artículo $32 \mathrm{~N}^{\circ} 6$ constitucional, denominado en este campo "principio de colaboración reglamentaria en materia impositiva” (cita STC Rol N ${ }^{\circ} 759$, C 25: "es la ley la encargada de precisar los elementos esenciales de la obligación tributaria, pudiendo la potestad reglamentaria de ejecución solo desarrollar aspectos de detalle técnico que, por su propia naturaleza, el legislador no puede regular, pero que este debe delimitar con suficiente claridad y determinación” y (C 23) cita otras sentencias que sustentan que "el ejercicio de la facultad reglamentaria debe limitarse a la aplicación de la ley, limitándose las facultades discrecionales, de manera que siempre exista solo una situación jurídicamente procedente. En consecuencia, el ámbito del ejercicio de esta facultad se limita a desarrollar aspectos técnicos que la ley no puede determinar, siempre dentro de contornos claramente definidos por el legislador. La ley debe, al menos, hacer determinable el tributo" (STC roles No 718, No 759 y No 773 , entre otras). Concluye esta parte con el C 25\%, indicando que "en síntesis, aquí hay una sola solución jurídicamente procedente que ha tendido a aplicarse uniformemente por la jurisprudencia ordinaria, constitucional $y$, recientemente, administrativa, en un mismo sentido y sin que la colaboración reglamentaria tenga una función específica que genere un efecto inconstitucional".

Respecto del derecho de igualdad ante la ley, en su C $28^{\circ}$ el TC cita su jurisprudencia reiterada en materia de igualdad ante la ley ${ }^{32} \mathrm{y}$, en su C $30^{\circ}$, interdicción de la discriminación arbitraria ${ }^{33}$.

Cierra el fallo con dos argumentos adicionales, en su C 310 ("Que en la presente causa siquiera existe diferencia de trato respecto de la sociedad requirente con otras que se encuentren en condición similar. Como ya se afirmó, toda sociedad que se encuentre en la misma posición jurídica que la requirente estará obligada, en principio, al pago de patente municipal, y corresponderá a los tribunales ordinarios determinarlo") y C 32。 ("Que,

$32 \quad$ El principio de igualdad consiste en "que las normas juridicas deben ser iguales para todas las personas que se encuentren en las mismas circunstancias $y$, consecuencialmente, diversas para aquellas que se encuentren en situaciones diferentes. No se trata, por consiguiente, de una igualdad absoluta sino que ha de aplicarse la ley en cada caso conforme a las diferencias constitutivas del mismo. La igualdad supone, por lo tanto, la distinción razonable entre quienes no se encuen-

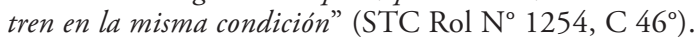

33 "Que esta Magistratura ha fallado que para efectos "de dilucidar si, en el conflicto que se ha planteado, se produce una infracción al derecho a la igualdad ante la ley, es necesario determinar, en primer lugar, si realmente estamos frente a una discriminación o diferencia de trato entre personas que se encuentran en una situación similar para, luego, examinar si tal diferencia tiene el carácter de arbitraria importando una transgresión a la Carta Fundamental' (STC Rol N ${ }^{\circ}$ 1340 y en el mismo sentido, entre otras, STC Roles $\mathrm{N}^{\circ}$ s 790, 825, 829). 
por lo demás, el artículo 24, inciso primero, del D.L. N 3.063 no grava especialmente a las sociedades de inversión, sino que establece una norma procedimental sobre el domicilio del pago de patente municipal”).

\section{(4) Sentencias recientes de la Corte Suprema en ReCurso de CASACIÓN}

Entre el año 2014 y 2017 , es posible encontrar otras sentencias que han referido la materia, sobre todo en casación en el fondo.

\section{(4.1.) "I. MUNiCipalidad DE MACUl CON SOCIEDAD INVERSIONES AF LIMITADA" (2014) ${ }^{34}$}

En este caso, la Corte Suprema sostiene que una sociedad que solo se ha dedicado a realizar inversiones de carácter privado sin interactuar con terceros, no se encuentra eximida de pagar patente, no solo por estar realizando una actividad lucrativa, sino porque el pago de patente es la contribución que le habilita para desarrollar las actividades propias de su giro, no resultando relevante si efectivamente las realizó (C $4^{\circ}$ de la sentencia). Dicha conclusión no vulnera el principio de reserva legal, pues el Reglamento de la LRM fue dictado por el Presidente de la República en virtud de las facultades otorgadas por la Constitución para la ejecución de las leyes, es decir, tiene por objeto la complementación y regulación de las ellas, lo cual conduce a la certeza y seguridad en su aplicación por parte de sus destinatarios. En virtud de lo anterior, el Reglamento aludido no se ha excedido en su función de complementar y desarrollar lo dispuesto en el artículo 23 de la LRM, al dar un concepto amplio y residual de la actividad terciaria, pues este se corresponde con el sentido y espíritu que la ley le ha dado a esta regulación a través de una separación clásica de actividades económicas, dentro de las cuales se comprenden las actividades lucrativas realizadas por las sociedades de inversión (C $5^{\circ}$ de la sentencia). La modificación que la Ley No 20.033 introdujo al artículo 24 de la Ley de Rentas Municipales solo adquiere sentido en cuanto las sociedades de inversión y las sociedades de profesionales se encuentran gravadas con patente municipal, circunstancia que llevó al legislador a precisar cuál era el domicilio a considerar cuando estas desarrollaran sus actividades sin registrar un domicilio comercial que permitiera determinar la comuna en la cual deben pagar su patente, y que será aquel que tengan registrado ante el SII (C 60).

34 Corte Suprema, Rol No 24.214 de 9 de abril de 2015, I. Municipalidad de Macul con Sociedad Inversiones AF Limitada (2014). Disponible en Base de Datos VLex https://cortesuprema-justicia.vlex.cl/vid/i-municipalidad-macul-inversiones-564694530 [Visitado: 2 de mayo de 2017]. 


\section{(4.2.) "I. Municipalidad DE Las Condes Con María Merino Blanco I" E “I. MUNiCIPALIDAD DE LAS CONDES CON Ximena MERINO BLANCO II"35}

En ambos casos, la Corte Suprema sustenta que la persona natural que realiza inicio de actividades para los efectos de tributación de las rentas que aquellas le generen, no puede calificarse como persona jurídica ni ser tratada, en este caso, como una sociedad de inversión. Y es posible inferir que el legislador no ha pretendido gravar con la patente municipal a las personas naturales que realicen actividades rentísticas y, por tanto, este impuesto solo alcanza a quienes contractualmente se constituyen en una sociedad (C $5^{\circ}$ y C $6^{\circ}$ de la sentencia). En consecuencia, pretendiendo la municipalidad ejecutante el cobro de patente municipal respecto de una persona natural que, si bien explota una actividad económica, lo hace sin organizarse como persona jurídica y, por ende, no es sujeto pasivo del referido tributo, corresponde acoger la excepción del artículo 464 No 14 del Código de Procedimiento Civil, la nulidad de la obligación. En efecto, el principio de legalidad o de reserva legal en materia tributaria determina que no se cumplen los presupuestos que los artículos 23 y siguientes de la LRM indican para que se cobre patente municipal, todo lo cual conduce a concluir que no ha podido devengarse respecto de la ejecutada patente comercial alguna, lo que deviene en la nulidad de la obligación cuya ejecución se persigue (C $11^{\circ}$ de la sentencia).

\section{(4.3.) “I. MUNICIPALIDAD DE CERRILLOS CON RENTA E INVERSIONES ARBA"36}

En esta causa, la Corte acoge el recurso de casación en el fondo contra sentencia que ordena pago de patente municipal, dado que la Municipalidad dictó con anterioridad una resolución (de 14 de julio de 2011, en cumplimiento de dictámenes de la CGR, que señalan que las sociedades de inversión de carácter pasivo están exentas del pago de la contribución municipal) que reconoció a la ejecutada la condición de ser una sociedad de inversión pasiva y la liberó del pago de patente municipal y dicha situación se mantiene en el tiempo pues no ha existido acto alguno que

\footnotetext{
35 Corte Suprema, 29 de diciembre de 2015, Rol No 5602-2015, "I. Municipalidad de Las Condes con Ximena Merino Blanco II", recurso de casación en el fondo. Disponible en Base de Datos LegalPublishing, Cita Online: CL/JUR/8115/2015 [Fecha de visita: 24 de abril de 2017].

36 Corte Suprema, 5 de diciembre de 2016, Rol No 47588-2016I, "Municipalidad de Cerrillos con Renta e Inversiones ARBA", recurso de casación en el fondo. Disponible en Base de Datos MicroJuris, Cita Online: MJCH_MJJ47340 | ROL:47588-16, MJJ47340 [Fecha de visita: 24 de abril de 2017].
} 
modifique o deje sin efecto la resolución al menos hasta el momento en que se decide demandar ejecutivamente, lo que ocurre en noviembre de 2013, cuando se entiende que la Municipalidad realizó un acto positivo que da cuenta del cambio de criterio en relación a la materia. Dicho acto formal de la Municipalidad (resolución de 14 de julio de 2011) quedó amparado con la presunción de legalidad, imperio y exigibilidad frente a sus destinatarios como señala el artículo $3^{\circ}$ de la Ley $\mathrm{N}^{\circ} 19.880$. Esta condición de imperio o exigibilidad puede ser suspendida por la propia autoridad administrativa, pero en el caso sub lite no ocurrió. Se basa lo anterior en la Teoría de los Actos Propios que se funda en el principio general del derecho de la buena fe, que obliga a una conducta leal y honesta e impide contradecir lo dicho o hecho por la misma institución de un modo aparente y ostensible con perjuicio de un tercero, que fiado de esas apariencias contrae una obligación o sufre un perjuicio en su persona o en su patrimonio ${ }^{37}$.

$37 \quad$ La sentencia profundiza en los considerandos 9 a 11 :

"C 9०: Que frente al principio antes referido y aún con mayor fuerza, se debe acudir igualmente a la doctrina de los actos propios que reconoce sus primeros origenes en el Derecho Romano, donde, pese a no haberse estructurado con los perfiles de homogeneidad y generalidad, propios de una norma jurídica, vertida inicialmente en la máxima 'venire contra factum proprium non valet' se recogió más tarde en sus líneas esenciales por la codificación de Justiniano, en la que se intentó consagrarla como criterio de aplicación general, según se evidencia en el Digesto, que establece una regla de acuerdo con la cual nadie puede cambiar su voluntad en perjuicio de otro.

Divulgada por los glosadores, perfeccionó enseguida su formulación como doctrina en la obra de los comentaristas medievales, instalándose posteriormente en los diversos ordenamientos jurídicos. Nuestro sistema normativo no establece una regulación especifica en relación con la teoría de los actos propios, la cual, sin embargo, ha adquirido amplia acogida durante los últimos tiempos en la doctrina de los autores y en la jurisprudencia, donde se la reconoce como un criterio orientador derivado del principio general de la buena fe-concebida esta en su faz objetiva-a la que se refiere el artículo 1546 inciso $3^{\circ}$ del Código Civil cuando prescribe que los contratos deben ejecutarse de buena fe y que, por consiguiente, obligan no solo a lo que en ellos se expresa sino a todas las cosas que emanan precisamente de la naturaleza de la obligación o que por la ley o costumbre pertenecen a ella.'

C 10': 'Que siempre en referencia a la buena fe considerada como principio inspirador de la regla de los actos propios, se ha dicho por la doctrina de los autores, principal fuente de elaboración conceptual de dicho instituto, ante la ausencia de regulación normativa sobre el tema: 'Si se observan los casos en que los autores y los tribunales han afirmado la vigencia del venire contra factum proprium', se puede advertir que en todos ellos está en juego la protección de la buena fe objetiva, es decir, del deber de no defraudar deslealmente la confianza que un tercero ha podido legitimamente depositar en un determinado estado de hecho provocado voluntariamente por las palabras o las actuaciones de una persona. Es la lesión injustificada de la buena fe la que proporciona una razón suficientemente fuerte para poner de cargo del que se contradice el riesgo de su inconsistencia' (Hernán Corral Talciani. 'La doctrina de los actos propios en el Derecho de Familia Chileno'. Cuadernos de Extensión Jurídica $N^{\circ} 18$, Universidad de los Andes; páginas 105 y 106).

'La conducta contraria es una contravención o una infracción del deber de buena fe. Ya antes hemos señalado que el hecho de que una persona trate, en una determinada situación jurídica, de obtener la victoria en un litigio, poniéndose en contradicción con su conducta anterior, constituye un proceder injusto y falta de lealtad. He aqui por donde la regla, según la cual, nadie puede ir contra sus propios actos, se anuda estrechamente con el principio de derecho que manda comportarse de buena fe en las relaciones juridicas' (Luis Diez Picazo. 'La doctrina de los actos propios. 
Asimismo, la Corte recuerda que uno de los principios del Derecho Administrativo es el de la protección de la confianza legítima, esto es, que las actuaciones de los poderes públicos generan la confianza entre los destinatarios de sus decisiones. Lo anterior vinculado directamente con el principio de conservación del acto administrativo, de la buena fe y de la seguridad jurídica, los que constituyen resguardos de la tutela invalidatoria ejercida por la propia Administración en relación con sus actos. Este principio tiene especial aplicación en el caso de autos donde un contribuyente contaba con un documento emanado de la Municipalidad ejecutante que lo autorizaba a funcionar como sociedad de inversión pasiva, exenta del pago de la patente municipal a la luz de lo que era la jurisprudencia administrativa de la CGR en la época en que había sido dictada la resolución y que la Municipalidad hizo suya al plasmarlo así expresamente $\left(C 8^{\circ}\right)$.

\section{(4.4.) “Christian Guillermo Farr Gaete Con I. Municipalidad DE LA SERENA"38}

En esta causa, el reclamante de ilegalidad ${ }^{39}$ interpone recurso de casación en el fondo contra la sentencia de la Corte de Apelaciones, que no hizo lugar al reclamo de ilegalidad municipal impetrado contra Ordinario municipal (a través del cual se le notificó la morosidad en el pago de patente municipal), a través del cual se le notificó la morosidad en el pago de patente municipal. La Corte Suprema desestima el recurso de casación.

Como en los demás casos, se cuestiona por el recurrente la acción de la Municipalidad en orden a cobrar patente municipal de una sociedad de inversión pasiva (sobre la base de la jurisprudencia administrativa de la

Estudio critico sobre la jurisprudencia del Tribunal Supremo'. Citado por María Fernanda Ekdahl Escobar en 'La doctrina de los actos propios'. Editorial Juridica de Chile. Páginas 72 y 73)." C 11०: "Que debe apuntarse que, en general, se entiende que la aplicación de la doctrina en análisis requiere la concurrencia copulativa de los siguientes requisitos: a.- Una conducta juridicamente relevante y eficaz por parte del sujeto, manifestada con anterioridad a aquella que, luego, pretende contradecir. b. - Una pretensión antagónica con el comportamiento precedente, exteriorizada mediante el ejercicio, por el mismo sujeto, de un derecho subjetivo, originándose con ello una situación litigiosa debido a la contradicción de ambas conductas, con afectación del principio de la buena fe. c.- Perjuicio grave para terceros que han ajustado su proceder a la conducta anterior y que resultan afectados por el cambio posterior de esta; $y$ d.- Identidad entre el sujeto que desarrolló la conducta original y el que, con posterioridad, pretende desconocerla, desplegando un comportamiento en sentido contrario."

38 Corte Suprema, 30 de marzo de 2017, Rol No 58992-2016, "Christian Guillermo Farr Gaete con I. Municipalidad de La Serena”, recurso de casación (Reclamo de Ilegalidad). Disponible en Base de Datos LegalPublishing, Cita Online: CL/JUR/1337/2017 [Fecha de visita: 24 de abril de 2017].

39 Esta acción se encuentra reglamentada en el articulo 141 de la ley 18.695, orgánica constitucional de municipalidades. Ver, en doctrina, la explicación, en Hunter Ampuero ( 2014) 196. 
CGR), lo que atentaría contra el principio de reserva de ley en un sentido constitucional, y obedecería a una actuación ilegal en cuanto no estaría este tipo de sociedades sujetas al pago de impuesto municipal de acuerdo lo señala la ley (siendo, entonces, una interpretación extensiva y entonces, no aceptable).

La Corte Suprema cuestiona el recurso presentado por el contribuyente, por cuestiones de fondo y de forma. En cuanto al fondo, en su C 70 manifiesta: "Que acorde a la normativa referida, para resolver si una persona natural o jurídica es sujeto pasivo de la obligación tributaria del pago de patente municipal, es indispensable determinar si la actividad que despliega está comprendida dentro del hecho gravado descrito en la ley, siendo del caso señalar que aquella por la que el actor inició actividades, esto es, construcción de obras menores y arriendo de inmuebles amoblados o con equipos y maquinaria, es sin duda una actividad comercial, de carácter terciario que está afecta al pago de patente. En este orden de ideas es imprescindible señalar que no se está gravando al actor por percibir rentas en carácter de persona natural, sino que por desarrollar un giro que constituye una actividad terciaria, sin que hasta la fecha haya puesto fin al giro iniciado."

Añade, en su C $8^{\circ}$, que "el giro del reclamante comprende la ejecución de actividades que importan la obtención de lucro o ganancia y, por consiguiente, configuran un hecho gravado en el mencionado artículo 23, como acertadamente lo consideró la sentencia que a través de este arbitrio se cuestiona, toda vez que, como se anunció, se trata de actividades terciarias de acuerdo a la definición del artículo $2^{\circ}$ del Decreto Supremo $\mathrm{N}^{\circ}$ 484, que constituye el Reglamento para la aplicación de los artículos 23 y 24 del Decreto Ley N³.063.”

Respecto del siguiente argumento, en su C 90 el sentenciador sostiene que "en cuanto al reproche concreto que plantea la recurrente, se debe señalar que yerra este al estimar que, si no hay ejercicio efectivo de las actividades gravadas, no debe pagar patente municipal, desde que este gravamen es semestral y lo habilita para desarrollar las actividades a que se refiere el artículo 23 del referido Decreto Ley, sin que se requiera el ejercicio efectivo. De lo contrario, el pago se haría una vez cumplido el período y se procedería a solucionar una patente proporcional a la época en que realizó alguna actividad, lo que por cierto es insostenible ${ }^{40}$.

40 Es semejante el razonamiento en este punto, en la sentencia de la Corte de Apelaciones de Santiago, "I. Municipalidad de Providencia con Inversiones Los Añańucas Limitada", al sostener que yerra la denunciada al estimar que si no hay ejercicio efectivo de tales actividades no debe pagar patente municipal, desde que este gravamen constituye la contribución que le habilita para desarrollar las actividades propias del giro, sin que se requiera el ejercicio efectivo. De lo contrario, el pago se haría una vez cumplido el período y se procedería a solucionar una patente proporcional a la época en que realizó alguna actividad y no con anterioridad al mismo (C $7^{\circ}$ y $\mathrm{C} 8^{\circ}$ de la sentencia de la Corte de Apelaciones). Por lo de- 


\section{CONCLUSIONES}

Este tipo de casos no solo es interesante porque puede observarse que es objeto de litigación hasta el presente, sino también porque permite mostrar que tanto los aspectos legales como los aspectos constitucionales referidos a tributos son susceptibles de ventilarse en instancias tan diversas como Contraloría General de la República, Cortes de Apelaciones, Corte Suprema, y Tribunal Constitucional, y muestra además las dificultades que esto implica en términos de coordinación institucional como en materia de interpretación constitucional y legal.

Luego de que esta clase de asuntos se disputen en diversos foros y en diversos aspectos a través de más de una década, como se ha mostrado en este estudio, se ha generado algún consenso en los principales extremos envueltos en la tributación local de las sociedades de inversión pasiva y de los casos cercanos a esta (como la tributación de personas naturales, o de sociedades de objeto social múltiple).

Finalmente, a partir de lo que claramente se desprende de las decisiones judiciales analizadas, es de destacar la recepción de principios en el ámbito del Derecho Tributario, respecto del cual se defiende una interpretación legal tan estricta (caso "Christian Guillermo Farr Gaete con I. Municipalidad de La Serena”). Con la incorporación de principios como categorías interpretativas tales como la teoría de los actos propios, los principios de buena fe y de confianza legítima, se altera radicalmente la solución jurídica estándar aplicable al caso, y se pone en entredicho la teoría general de la obligación tributaria como obligación legal de derecho estricto y de interpretación estricta ${ }^{41}$, y la teoría declarativa del acto administrativo y del acto judicial en materia de configuración de la obligación tributaria ${ }^{42}$.

más, cabe señalar que el artículo 24 inciso $2^{\circ}$ de la Ley de Rentas Municipales -incorporado por la Ley No 20.033, de 2005- dispone que las sociedades de inversión pagan la patente en la comuna correspondiente al domicilio declarado ante el SII, a menos que registren domicilio comercial. De ello se sigue que es el mismo legislador el que considera que tal clase de sociedades tienen el carácter de sujetos pasivos del tributo examinado. En consecuencia, resulta correcto el rechazo de la petición de la sociedad denunciada en cuanto se declare no estar afecta al pago de patente municipal, persona jurídica, que no está considerada en los casos de excepción que contempla el artículo 27 de la referida Ley (C 9o de la sentencia de la Corte de Apelaciones).

41 Avilés (2014)19.

42 Ver al respecto, Russo (2001) 18 y ss. 


\section{Bibliografía CitAdA}

Avilés Hernández, Víctor Manuel (2014). Legalidad Tributaria y Mecanismos Antielusión, Editorial Jurídica de Chile, Santiago.

Cross, Rupert y Harris, J.W. (2012), El Precedente en el Derecho Inglés, Marcial Pons, Madrid. Traducido por María Angélica Pulido, Precedent in English Law, Oxford University Press (4a edición, 1991).

Hunter Ampuero, Iván (2014). Reclamo de ilegalidad municipal en la jurisprudencia: caos interpretativo y criterios dudosos. Rev. derecho (Valdivia), Diciembre 2014, Vol. 27, No 2, pp.191-215.

Massone Parodi, Pedro (2013). Principios de Derecho Tributario, Tomo

I, Thomson Reuter, Santiago de Chile (3a Edición).

Romero García, Felipe (2005), El Valor Sistema Tributario: acerca de su integración entre los principios de la imposición, Servicio de Publicaciones UCA, Cádiz.

Russo, Pasquale (2001), La Obligación Tributaria, en Tratado de Derecho Tributario, Andrea Amatucci (Dir.), Temis, Bogotá, pp. 17-43.

\section{JURISPRUDENCIA CITADA}

\section{Cortes de ApElaCiones}

Corte de Apelaciones de Santiago, sentencia de 23 de marzo de 2005, Rol No 1371-2005. "Inversiones Extranjeras Cementos Bío-Bío con Municipalidad de Providencia I", desestimatoria. Disponible en: http://corte.poderjudicial.cl/SITCORTEPORWEB/?opc_menu=7 [Visitado: 27 de abril de 2017].

Corte de Apelaciones de Santiago, sentencia de 26 de noviembre de 2010, autos Rol N 8583-2009, "Inversiones Rotondo Limitada contra I. Municipalidad de Las Condes". reclamo de ilegalidad. Disponible en: http://corte.poderjudicial.cl/ SITCORTEPORWEB/?opc_menu=7 [Visitado: 27 de abril de 2017].

Corte de Apelaciones de Santiago, sentencia de 30 agosto de 2011, Rol No 1092-11, "Inversiones El Paso Limitada con Municipalidad de Providencia". Disponible en Base de Datos MicroJuris, Cita: MJCH_MJJ29206 | ROL:1092-11, MJJ29206 [Fecha de visita: 24 de abril de 2017].

Corte de Apelaciones de Santiago, sentencia de 26 de junio de 2012,

Rol No 5.776-2012, "Contraloría General con Municipalidades de Vitacura, Providencia, Macul y La Granja I", recurso de protección. Disponible en: http://corte.poderjudicial.cl/SITCORTEPORWEB/ [Fecha de visita: 24 de abril de 2017]. 
Corte de Apelaciones de Santiago, sentencia de 13 de diciembre de 2016, Rol No 1459-2016, "I. Municipalidad de Providencia con Inversiones Los Añañucas Limitada", reclamo de ilegalidad. Disponible en Base de Datos LegalPublishing, Cita Online: CL/ JUR/8868/2016 [Fecha de visita: 24 de abril de 2017].

\section{CORTE SUPREMA}

Corte Suprema, sentencia de 8 de marzo de 2007, Rol No 1492-2006, "Inversiones Extranjeras Cementos Bío-Bío con Municipalidad de Providencia II", recurso de casación, Disponible en: http://corte. poderjudicial.cl/SITCORTEPORWEB/?opc_menu=7 [Visitado: 27 de abril de 2017].

Corte Suprema, sentencia de 6 de noviembre de 2012, Rol No 59842012, "Contraloría General con Municipalidades de Vitacura, Providencia, Macul y La Granja II", sentencia en apelación, Disponible en Base de Datos VLex: https://corte-suprema-justicia. vlex.cl/vid/ilustre-municipalidad-santiago-contralor-436095386 [Fecha de visita: 24 de abril de 2017]

Corte Suprema, sentencia de 3 de julio de 2012, Rol No 27912012, "Municipalidad de Zapallar contra Contraloría Regional de Valparaíso", recurso de protección, estimatorio. Disponible en: http://suprema.poderjudicial.cl/SITSUPPORWEB/ DownloadFile.do?TIP_Documento=3\&TIP_Archivo=1\&COD_ Opcion=1\&COD_Corte $=1 \&$ CRR_IdTramite $=1095904 \& C R R \_$ IdDocumento $=689549$ [Fecha de visita: 24 de abril de 2017].

Corte Suprema, sentencia de 9 de abril de 2015, Rol 24.214-2014, "I. Municipalidad de Macul con Sociedad Inversiones AF Limitada". Disponible en Base de Datos VLex, https://corte-suprema-justicia. vlex.cl/vid/i-municipalidad-macul-inversiones-564694530 [Visitado: 2 de mayo de 2017].

Corte Suprema, sentencia de 9 de abril de 2015, Rol No 24214-2014, "I. Municipalidad de Macul con Sociedad Inversiones AF Limitada", Recurso de Casación en el Fondo. Disponible en Base de Datos LegalPublishing, Cita Online: CL/JUR/2000/2015. [Fecha de visita: 24 de abril de 2017].

Corte Suprema, sentencia de 29 de diciembre de 2015, Rol No 57652015, "I. Municipalidad de Las Condes con Ximena Merino Blanco I", recurso de Casación en el Fondo. Disponible en Base de Datos LegalPublishing, Cita Online: CL/JUR/8114/2015 [Fecha de visita: 24 de abril de 2017].

Corte Suprema, sentencia de 29 de diciembre de 2015, Rol No 56022015, "I. Municipalidad de Las Condes con Ximena Merino Blanco 
II", recurso de casación en el fondo. Disponible en Base de Datos LegalPublishing, Cita Online: CL/JUR/8115/2015 [Fecha de visita: 24 de abril de 2017].

Corte Suprema, sentencia de 5 de diciembre de 2016, Rol No 475882016, "Municipalidad de Cerrillos con Renta e Inversiones ARBA", recurso de casación en el fondo. Disponible en Base de Datos MicroJuris, Cita Online: MJCH_MJJ47340 | ROL:47588-16, MJJ47340 [Fecha de visita: 24 de abril de 2017].

Corte Suprema, sentencia de 30 de marzo de 2017, Rol No 589922016, "Christian Guillermo Farr Gaete con I. Municipalidad de La Serena", recurso de casación (Reclamo de Ilegalidad). Disponible en Base de Datos LegalPublishing, Cita Online: CL/JUR/1337/2017 [Fecha de visita: 24 de abril de 2017].

\section{SENTENCIAS DEL Tribunal Constitucional}

Tribunal Constitucional, 9 de octubre de 2008, Rol No 12422008, Requerimiento de inaplicabilidad deducido por Inversiones Las Perdices Limitada respecto de los artículos 23 y 24 del DL No 3063 -Ley de Rentas Municipales-, en causa Rol 3909/2008 de la Corte de Apelaciones de Santiago. Disponible en: www. tribunalconstitucional.cl/wp/desent.php?id=1242 [Fecha de visita: 24 de abril de 2017].

Tribunal Constitucional, 22 de octubre de 2008, Rol No 12562008, Requerimiento de inaplicabilidad de Inversiones Integradas S.A. respecto de los artículos 23 y 24 del Decreto Ley No 3.063, en causa Rol 6799-2007 de la Corte Suprema. Disponible en: www. tribunalconstitucional.cl/wp/desent.php?id=1256 [Fecha de visita: 24 de abril de 2017].

Tribunal Constitucional, 8 de abril de 2010, Rol No 1390-09-INA, Requerimiento de inaplicabilidad por inconstitucionalidad de Inversiones San Lorenzo Internacional S.A., respecto del artículo $1^{\circ}$ inciso segundo de la Ley 18.046,en Rol 5916-2008 de la Corte Suprema. Disponible en: www.tribunalconstitucional.cl/wp/desent. php?id=1390 [Fecha de visita: 24 de abril de 2017].

Tribunal Constitucional, Rol No 1401-09-INA, 11 de junio de 2009, Requerimiento presentado por Inversiones Persea Limitada, sobre acción de inaplicabilidad por inconstitucionalidad del inciso primero del artículo 23 e inciso primero del artículo 24 del Decreto Ley No 3.063, sobre rentas municipales en el recurso Rol No 1.024-2009 de la Corte de Apelaciones de Santiago, en contra de la sentencia del $17^{\circ}$ Juzgado Civil de Santiago Rol No 8.046. Disponible en: www. 
tribunalconstitucional.cl/wp/desent.php?id=1401 [Fecha de visita: 24 de abril de 2017].

Tribunal Constitucional, 20 de julio de 2010, Rol No 1453-09INA, Requerimiento de inaplicabilidad por inconstitucionalidad de Sociedad Inversiones Las Lilas Dos Limitada respecto de los artículos 23 y 24 del Decreto Ley No 3.063, de 1979 -sobre Rentas Municipales-, en los autos Rol No 3606-2009, sobre el recurso de casación en el fondo interpuesto ante la Corte Suprema en contra del fallo de la Corte de Apelaciones de Santiago que rechazó el reclamo de ilegalidad municipal deducido en contra del cobro de patente que ha dispuesto la Municipalidad de Providencia. Disponible en: www. tribunalconstitucional.cl/wp/desent.php?id=1453 [Fecha de visita: 24 de abril de 2017].

Tribunal Constitucional, 20 de julio de 2010, Rol No 1454-09INA, Requerimiento de inaplicabilidad por inconstitucionalidad de sociedad Inmobiliaria Lomas de Quelén S.A. respecto de los artículos 23 y 24 del Decreto Ley No 3.063, de 1979 -sobre Rentas Municipales-, en los autos Rol No 2210-2009, sobre recurso de casación en el fondo interpuesto ante la Corte Suprema en contra del fallo de la Corte de Apelaciones de Santiago que rechazó el reclamo de ilegalidad municipal deducido en contra del cobro de patente que ha dispuesto la Municipalidad de Santiago respecto de la referida sociedad. Disponible en: www.tribunalconstitucional.cl/wp/desent. php?id=1454 [Fecha de visita: 24 de abril de 2017].

Tribunal Constitucional, 23 de diciembre de 2009, Rol 1534-09-

INA, Requerimiento de inaplicabilidad por inconstitucionalidad de Inversiones del Mar S.A., respecto de los artículos 23 y 24 del DL 3063 de la Ley de Rentas Municipales, en Rol No 1676-2009 de la Corte de Apelaciones de Santiago. Disponible en: www. tribunalconstitucional.cl/wp/desent.php?id=1534 [Fecha de visita: 24 de abril de 2017].

Tribunal Constitucional, 15 de junio de 2010, Rol No 172410-INA, Acción de inaplicabilidad por inconstitucionalidad de Inversiones Deportivas Vińa del Mar S.A. respecto de los artículos 23 y 24 del Decreto Ley No 3063, de 1979, sobre Rentas Municipales, en los autos Rol No 1677-2009 sobre reclamo de ilegalidad interpuesto ante la Corte de Apelaciones de Valparaíso en contra de la I. Municipalidad de Valparaíso. Disponible en: www. tribunalconstitucional.cl/wp/desent.php?id=1724[Fecha de visita: 24 de abril de 2017].

Tribunal Constitucional, Rol No 1873-10-INA, 25 de agosto de 2011, Requerimiento de inaplicabilidad por inconstitucionalidad presentado por Inversiones Rotondo Limitada respecto del inciso segundo del artículo 768 del Código de Procedimiento Civil, en los 
autos Rol No 8583-2009 sobre reclamo de ilegalidad interpuesto ante la Corte de Apelaciones de Santiago en contra de Municipalidad de Las Condes. Disponible en: www.tribunalconstitucional.cl/wp/ desent.php?id=1873 [Fecha de visita: 24 de abril de 2017].

Tribunal Constitucional, 14 de marzo de 2013, Rol No 2104-11INA, Requerimiento de inaplicabilidad por inconstitucionalidad presentado por Inversiones MC \& MC II Limitada respecto de los artículos 23, inciso tercero y 24, inciso primero, ambos del Decreto Ley $\mathrm{N}^{\circ} 3063$, Ley sobre Rentas Municipales, en los autos sobre reclamo de ilegalidad caratulados "Inversiones $\mathrm{MC} \& \mathrm{MC}$ II Limitada con Ilustre Municipalidad de Las Condes", de que conoce la Corte de Apelaciones de Santiago, bajo el Rol N ${ }^{\circ} 1.412-$ 2010. Disponible en: www.tribunalconstitucional.cl/wp/desent. php?id=2104 [Fecha de visita: 24 de abril de 2017].

Tribunal Constitucional, 14 de marzo de 2013, Rol No 2134-11INA, Requerimiento de inaplicabilidad por inconstitucionalidad presentado por Inversiones Mañío Limitada respecto de los artículos 23, inciso tercero, y 24, inciso primero, ambos del Decreto Ley $\mathrm{N}^{\circ} 3.063$, Ley sobre Rentas Municipales, en los autos sobre reclamo de ilegalidad caratulados "Inversiones Mañío Limitada con I. Municipalidad de Las Condes", de que conoce la Corte de Apelaciones de Santiago, bajo el Rol No 1414-2010, en actual casación en el fondo ante la Corte Suprema. Disponible en: www. tribunalconstitucional.cl/wp/desent.php?id=2134 [Fecha de visita: 24 de abril de 2017].

Tribunal Constitucional, 14 de marzo de 2013, Rol No 2135-11INA, Requerimiento de inaplicabilidad por inconstitucionalidad presentado por Inversiones Lingue Limitada respecto del artículo 23, inciso tercero, del Decreto Ley $\mathrm{N}^{\circ} 3.063$, Ley sobre Rentas Municipales, en los autos sobre reclamo de ilegalidad caratulados "Inversiones Lingue Limitada con I. Municipalidad de Las Condes", de que conoce la Corte de Apelaciones de Santiago, bajo el Rol No 1416-2010, en actual casación en el fondo ante la Corte Suprema. Disponible en: www.tribunalconstitucional.cl/wp/desent. php?id=2135 [Fecha de visita: 24 de abril de 2017].

Tribunal Constitucional, 14 de marzo de 2013, Rol No 2141-11INA, Requerimiento de inaplicabilidad por inconstitucionalidad presentado por Inversiones Luma Limitada respecto de los artículos 23 , inciso tercero, y 24, inciso primero, ambos del Decreto Ley $\mathrm{N}^{\circ}$ 3.063, Ley sobre Rentas Municipales, en los autos sobre recurso de casación en el fondo caratulados "Inversiones Luma Limitada con De la Maza Chadwick Francisco", de que conoce la Corte Suprema, bajo el Rol N 10.268-2011. Disponible en: www.tribunalconstitucional. $\mathrm{cl} / \mathrm{wp} /$ desent.php?id=2141 [Fecha de visita: 24 de abril de 2017]. 